\title{
Simulation of a Building and its HVAC system with an equation solver: Application to benchmarking.
}

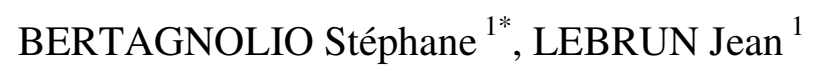

Thermodynamics Laboratory, University of Liège

Campus du Sart-Tilman, Bâtiment B49 (P33)

B-4000 LIEGE, BELGIUM

Tel : 32-(0)-366 $4800 \quad$ Fax : 32-(0)-366 4812

* stephane.bertagnolio@ulg.ac.be

This paper has been published in "Building Simulation: An International Journal" @ Tsinghua Press and Springer-Verlag 2008.

Paper DOI: 10.1007/s12273-008-8219-4

The original publication is available at www.springerlink.com

The correct citation of the paper is:

Bertagnolio, S., Lebrun, J. (2008) Simulation of a building and its HVAC system with an equation solver: Application to benchmarking. Building Simulation: An International Journal. 1(3): 234-250. 


\section{ABSTRACT}

The today - availability of powerful engineering equation solvers is opening very new possibilities in technical component modelling and in system simulation.

The simulation models, the "user guide" and the "reference guide" are all included in a same file. Reliable "reference" and "simplified" models are currently available for the building zone and for most HVAC components. Focus is given here on "simplified" models and on a simulation tool, called "Benchmark". This tool should help an auditor to make the best use of the limited information usually available about actual fuel and electricity consumptions and to get a very first evaluation of the actual performances of a given HVAC system. An example of such use is presented.

Another simulation tools and more information about the modelling of HVAC components will be presented in a further paper.

\section{KEYWORDS}

Building modelling, HVAC system modelling, Building Energy Audit, Benchmarking 


\section{LIST OF SYMBOLS}

albedo albedo

A wall area $\left(\mathrm{m}^{2}\right)$

C thermal capacity $(\mathrm{J} / \mathrm{K})$

$\mathrm{CO}_{2}$ or water capacity $(\mathrm{kg})$

CLF cooling load factor

$\mathrm{c}_{\mathrm{p}} \quad$ specific heat $(\mathrm{J} / \mathrm{kg}-\mathrm{K})$

ELF electrical load factor

F correction or increase factor

h combined convective - radiative heat transfer coefficient $\left(\mathrm{W} / \mathrm{m}^{2}-\mathrm{K}\right)$

HLF heating load factor

$\dot{H} \quad$ enthalpy flow rate (W)

I $\quad$ solar radiation $\left(\mathrm{W} / \mathrm{m}^{2}\right)$

M $\quad$ mass $(\mathrm{kg})$

MM molar mass $(\mathrm{g} / \mathrm{mol})$

$\mathrm{n}_{\mathrm{occ}} \quad$ number of occupants

$\Delta P \quad$ Pressure drop $(\mathrm{Pa})$

$\dot{Q} \quad$ heat flux or thermal power (W)

$\mathrm{R} \quad$ thermal resistance $(\mathrm{K} / \mathrm{W})$

SF solar factor

$\mathrm{t} \quad$ temperature $(\mathrm{C})$

$\mathrm{U} \quad$ internal energy $(\mathrm{J})$

V volume $\left(\mathrm{m}^{3}\right)$

$\dot{V} \quad$ volumetric flow rate $\left(\mathrm{m}^{3} / \mathrm{s}\right)$

W humidity ratio $(\mathrm{kg} / \mathrm{kg})$ 


$\begin{array}{ll}\dot{W} & \text { electrical power }(\mathrm{W}) \\ \mathrm{X} & \text { volumetric concentration, or control variable } \\ \alpha & \text { solar absorbance } \\ \mathcal{E} & \text { effectiveness } \\ \eta & \text { efficiency } \\ \rho & \text { density }\left(\mathrm{kg} / \mathrm{m}^{3}\right) \\ \tau & \text { time }(\mathrm{s})\end{array}$

\section{Subscripts}

1 initial value

a air

appl appliance

c consumed

cd condenser

$\mathrm{CO}_{2} \quad$ carbon dioxide

dp dewpoint

el electricity

ev evaporator

ex exhaust

exfiltr exfiltration

f fictitious

FCU fan coil unit

in indoor

inf infiltration

n nominal

occ occupancy 


$\begin{array}{ll}\text { out } & \text { outdoor } \\ \text { r } & \text { refrigerant } \\ \text { red } & \text { reduced } \\ \text { s } & \text { sensible } \\ \text { sh } & \text { shaft } \\ \text { su } & \text { supply } \\ \text { surf } & \text { surface } \\ \text { tot } & \text { total } \\ \text { twb } & \text { wet bulb temperature } \\ \text { TU } & \text { terminal unit } \\ \text { u } & \text { useful } \\ \text { vent } & \text { ventilation } \\ \text { w } & \text { water } \\ \text { wb } & \text { wet bulb } \\ \text { w } & \text { water }\end{array}$




\section{MAIN TEXT}

\section{Introduction}

Early developments of simulation tools were mostly oriented towards supporting system design, i.e. mainly the selection and sizing of HVAC components (Lebrun and Liebecq, 1988). The usefulness of simulation tools in further stages of the building life cycle appeared later, among others with the apparition of friendly engineering equation solvers and of reliable simulation models. Energy simulation may help all along the building life cycle, from early design until last audit and retrofit actions. Building and HVAC simulation models should therefore be continuously available, but in different forms, according to what is expected from the simulation and according to the information actually available.

Today, the simulation bottleneck is no more the computer, but the understanding of the user. Simulation models have therefore to be designed in such away to make easier this understanding.

Hopefully the equation solvers presently available (Klein, 2008) open the way to the development of fully transparent and fully adaptable simulation models, with all equations written as in a text book. This means that a simulation program, its user guide and its reference guide can be combined into only one file, fully readable and directly executable. Reference and detailed models of HVAC components may help a lot in the commissioning process, among others for functional performance testing (Visier and Jandon, 2004). These detailed models may also help a lot in the daily system management, among others for fault detection and diagnosis (Jagpal, 2006). More global (and simplified) simulation can be used in real time to "emulate" building energy management systems (Lebrun and Wang, 1993). New simulation capabilities are also appearing today in the domain of energy audit (Auditac, 2007; Harmonac, 2008).

In this paper, special attention is paid to this last use of building energy simulation tools. 


\section{Use of simulation tools for energy auditing}

Audit is required, among others, to identify the most efficient and cost-effective Energy Conservation Opportunities (ECOs), consisting in more efficient use or in (partial or global) replacement of the existing components.

Four audit stages are generally distinguished (André et al., 2006a):

1. The "benchmarking" helps in deciding if it is necessary to launch a complete audit procedure; it's based mainly on energy bills and basic calculations. A direct use of such global data would not allow the auditor to identify "good", "average" and "bad" energy performances. The experimental identification of HVAC consumptions is often almost impossible: these consumptions are, most of the time, not directly measured, but "mixed" with other ones (lighting, appliances etc.). Simulation is then of great help to define some, even very provisory, reference performances (or "benchmarks"), in view of a first qualification of the current building performances.

Without simulation, some arbitrary normalization had been required before any comparison of the recorded data on the studied installation with reference values deduced from case studies or from statistics.

2. The aim of the "pre-audit" (also called "Walk-through Audit" or "Inspection") is to identify the main defects and "energy conservation opportunities" (ECO's). Its results are supposed to orient the future "detailed" audit. The inspection consists in a visual verification of HVAC equipment, in an analysis of operating data records and in a systematic disaggregation of recorded energy consumptions. Thanks to parametric tuning, the building-HVAC simulation model can be fitted on the records actually available (very often no more than monthly fuel and electricity bills) in such a way to become a "baseline" 
simulation model, allowing the auditor to identify the main energy consumers (lighting, appliances, fans, pumps, chiller...) and to analyse the actual performance of the building

3. The "detailed" audit consists in a detailed and comparative evaluation of the ECOs previously selected. At this step even more, simulation is the key tool.

4. The "investment grade" audit concerns the detailed technical and economical engineering studies, justifying the costs of the retrofits.

This fourth audit stage brings the system (building + HVAC) to a new life cycle: new design, call for tenders, submissions, evaluations, installations, commissioning, etc.

Several simulation tools are being developed in the frame of the HARMONAC project (2008).

Focus is given, in the present paper, to a first one, called "BENCHMARK". This tool is used to compute the "theoretical" (or « reference ») consumptions of the building, supposed to be equipped with a "typical" HVAC system, including air quality, temperature and humidity control. The building is seen as a unique zone, described by a very limited number of parameters. This first simulation tool should help the auditor in getting, a very first impression about the performances of the system considered. Other simulations tools will be described in further papers. 


\section{Modelling}

For benchmarking, as for further audit actions, the simulation tool must handle with realism:

- building (static and dynamic) behaviour,

- weather and occupancy loads,

- comfort requirements and control strategies (air quality, air temperature and humidity),

- full air conditioning process and characteristics of all HVAC system components (terminal units, Air Handling Units, air and water distribution, plants)

The level of detail required for the calculation of heating/cooling demands can vary a lot from case to case:

- For heating calculations, the major issues are a correct description of the building envelope and an accurate evaluation of air renewal.

- For cooling calculations, the fenestration area and orientation, the intensity and distribution of internal gains, the ventilation rates and the geographical location appear as critical issues.

At benchmarking stage mainly, the simulation tools have also to be usable with a limited quantity of information only, depending on data actually available. These tools must be easyto-use, transparent, reliable, sufficiently accurate and robust.

The simulation tool presented here after includes models of both the building and the HVAC equipment. These models are submitted to different loads and interact at each time step with a control module (Figure 1).

The main phenomena involved in building dynamics are considered in order to compute realistic heating and cooling demands. Indeed, the indoor conditions of the zone come from the equilibrium established among many different influences. A compromise is made between the number of influences taken into account and the simplicity of the model: transient heat 
transfer through walls, energy storage in slabs, internal generated gains, solar gains through windows, infrared losses and, of course, ventilation and heating/cooling devices, are actually taken into account.

\subsection{Inputs, outputs and parameters}

The outputs, inputs and parameters must be selected according to the specific needs of the user. As in some other softwares, as TRNSYS for instance (Klein et al., 2004), the parameters are here defined as selected inputs which are not supposed to vary during the simulation.

The main outputs of the tool presented here are:

- Air quality and hygro-thermal comfort achievements: $\mathrm{CO}_{2}$ contamination, temperature, humidity, predicted percentage of dissatisfied (PPD), and predictd mean vote (PMV);

- Global power and energy consumptions : Fuel and Electricity consumptions;

- HVAC components specific demands;

- Performances of the mechanical equipments: COP, efficiencies...

The main inputs are:

- Weather data : hourly values of temperature, humidity, global and diffuse radiations;

- Nominal occupancy loads (in $\mathrm{W} / \mathrm{m}^{2}$ ), occupancy and installation functioning rates;

- Comfort requirements: air renewal, temperature and humidity set points;

- Control strategies : feedback on indoor temperature and relative humidity, feedforward on occupancy schedules and calendar.

The main parameters are:

- Dimensions, orientation and general characteristics of the building envelope (e.g. "heavy", "medium" or "light" thermal mass and walls U values).

- Sizing factors of the main HVAC components 
The main parameters described above are entered through the control panels. The other parameters of the model, as HVAC system characteristics, nominal performances and capacities are automatically computed through a pre-sizing calculation, or defined on the basis of default values, given in European standards prEN 13053 (2003) and prEN 13773 (2007). Other information as weather data and occupancy rate are provided in "lookup tables".

\subsection{Building Modelling}

\subsubsection{Indoor Conditions}

The indoor conditions $\left(\mathrm{CO}_{2}\right.$ contamination, global temperature and humidity) are computed by means of three different mass and energy balances. Indoor comfort indexes (PMV and PPD) are evaluated at each time step through classical Fanger's equations (1970).

\subsubsection{Sensible heat balance}

A sensible heat balance is made on the indoor node to compute the combined convective radiative indoor temperature.

A mono-zone building model is used here. It's based on a simplified equivalent R-C network including five thermal masses (Figure 2; Masy, 2006), corresponding to a large occupancy zone, surrounded by external glazed and opaque walls. This scheme corresponds to a typical office building, mainly composed of lattice structure and slabs.

The heat flow emitted by the surfaces of the walls (roof, floor, opaque frontages and windows), the enthalpy flow rate corresponding to ventilation and infiltration air and the internal sensible gains (including local heating/cooling and internal generated gains) are summed (eq. 1), in order to compute the energy storage inside the indoor environment (eq. 2 and 3). This energy storage is computed by the means of a first order differential equation. A correction factor $\left(\mathrm{F}_{\mathrm{a}, \mathrm{in}}\right.$, eq. 4) has to be applied to the air capacity in order to take into account the effect of the vertical air temperature gradient in the zone (Lebrun, 1978; Laret, 1980).

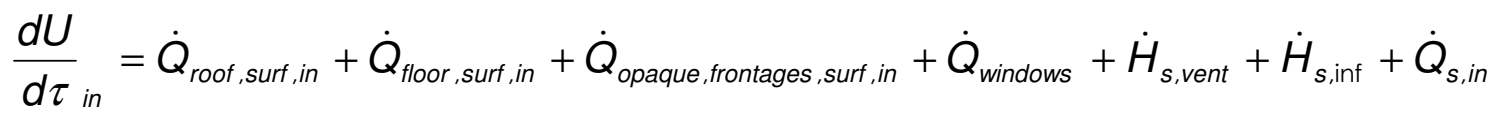




$$
\begin{aligned}
& \Delta U_{i n}=\int_{\tau 1}^{\tau 2} \frac{d U}{d \tau}{ }_{i n} d \tau \\
& \Delta U_{i n}=C_{i n} *\left(t_{a, i n}-t_{a, i n, 1}\right) \\
& C_{i n}=F_{a, i n} * V_{i n} * \rho_{a} * c_{p, a}
\end{aligned}
$$

\subsubsection{CO2 Balance}

A first mass balance is used to compute the $\mathrm{CO} 2$ concentration in the indoor environment.

The CO2 flow rate entering the zone is due to two main contributions (eqs. 5 to 11) :

- $\mathrm{CO} 2$ brought by ventilation (eq. 6), positive infiltration and negative exfiltration air flow rates (eq. 7),

- $\mathrm{CO} 2$ produced by the occupants (function of the occupant metabolic rate, eq. 8).

Treated ventilation air CO2 concentration is given as an output of the HVAC system model, while, for infiltration, it corresponds to outdoor air input data.

$$
\begin{aligned}
& \frac{d M}{d \tau}=\dot{M}_{C O 2, \text { in }}+\dot{M}_{C O 2, \text { inf }}+\dot{M}_{C O 2, \text { in }} \\
& \dot{M}_{C O 2, \text { vent }}=\dot{M}_{a, \text { ex, sup plyduct }} * \frac{M M_{C O 2}}{M M_{a}} * X_{C O 2, \text { ex , sup plyduct }}-\dot{M}_{a, \text { su, returnduct }} * \frac{M M_{C O 2}}{M M_{a}} * X_{C O 2, \text { in }} \\
& \dot{M}_{C O 2, \text { inf }}=\dot{M}_{a, \text { inf }} * \frac{M M_{C O 2}}{M M_{a}} * X_{C O 2, \text { out }}-\dot{M}_{a, \text { exfiltr }} * \frac{M M_{C O 2}}{M M_{a}} * X_{C O 2, \text { in }} \\
& \dot{M}_{C O 2, \text { in }}=\dot{M}_{C O 2, o c c}=n_{o c c} * \dot{M}_{C O 2, \text { peroccupant }} \\
& \Delta M_{C O 2, \text { in }}=\int_{\tau 1}^{\tau 2} \frac{d M}{d \tau}{ }_{C O 2, \text { in }} d \tau \\
& C_{C O 2, \text { in }}=M_{a, \text { in }} * \frac{M M_{C O 2}}{M M_{a}} \\
& \Delta M_{C O 2, \text { in }}=C_{C O 2, \text { in }} *\left(X_{C O 2, \text { in }}-X_{C O 2, \text { in }, 1}\right)
\end{aligned}
$$


The "CO2 capacity" introduced in equation 10 is here supposed to correspond to the mass of the air contained in the zone. A correction factor might be also introduced in order to take into account of $\mathrm{CO} 2$ absorption in the building materials (walls and furniture).

\subsubsection{Water Balance}

A second mass balance is made to compute the water content of the indoor air. The water flow rate entering the zone is due to three main contributions (eq. 12) :

- water brought by ventilation, positive infiltration and negative exfiltration air flow rates (eq.16 and 17),

- water produced by the occupants or local humidification devices (eq.18),

- water condensed by local cooling devices (eq. 18).

Water exchanges between air and walls or materials are roughly estimated in the present software. A correction factor $\left(F_{w, i n}\right)$ is here also applied to the air capacity; it's supposed to take into account of the effect of hygroscopic materials contained in the zone (Woloszyn, 1999).

$$
\begin{aligned}
& \frac{d M}{d \tau}{ }_{w, \text { in }}=\dot{M}_{w, \text { vent }}+\dot{M}_{w, \text { inf }}+\dot{M}_{w, \text { in }} \\
& \Delta M_{w, \text { in }}=\int_{\tau 1}^{\tau 2} \frac{d M}{d \tau}{ }_{w, \text { in }} d \tau \\
& \Delta M_{w, \text { in }}=C_{w, \text { in }} *\left(w_{\text {in }}-w_{\text {in, } 1}\right) \\
& C_{w, \text { in }}=F_{w, \text { in }} * V_{\text {in }} * \rho_{a} \\
& \dot{M}_{w, \text { vent }}=\dot{M}_{a, \text { ex, sup plyduct }} * w_{\text {ex,sup plyduct }}-\dot{M}_{a, \text { su, returnduct }} * w_{\text {in }} \\
& \dot{M}_{w, \text { inf }}=\dot{M}_{a, \text { inf }} * w_{\text {out }}-\dot{M}_{a, \text { exfiltr }} * w_{\text {in }} \\
& \dot{M}_{w, \text { in }}=\dot{M}_{w, \text { occ }}+\dot{M}_{w, \text { heating } T U}-\dot{M}_{w, \text { coolingtu }}
\end{aligned}
$$




\subsubsection{Walls thermal models}

A 2 RC $1^{\text {st }}$ order "two-port networks" model (Figure 3 ) is associated to each massive wall (Laret, 1980). The wall network (Figure 2) corresponds either to imposed temperature boundary conditions (for 'external' massive walls in contact with outdoor conditions) or to null heat flow boundary conditions (for ceiling and floor slabs separating two heated zones characterized by similar temperature profiles). The parameters of each "two-port network" are tuned through a frequency analysis based on the computation of the zone admittance matrix (Masy, 2006).

In the case of an "isothermal wall" (massive opaque frontage or roof slab), the absorbed solar radiation is injected on the outdoor surface node (Figure 4).

A correction heat flow (Bliss, 1961) varying from 45 to $100 \mathrm{~W} / \mathrm{m}^{2}$, is also used to take into account that the sky temperature is below the outdoor air temperature. These two effects (solar and sky radiations) are included in the corrected outdoor ("sol-air") temperature $t_{\text {out }}^{*}$ (eq. 19).

$t_{\text {out }}^{*}=t_{\text {out }}+\left(\dot{Q}_{\text {sun }}-\dot{Q}_{\text {sky }}\right) * R_{\text {surf }, \text { out }}$

Solar radiation absorbed by the wall is computed as follow :

$$
\begin{aligned}
& \dot{Q}_{\text {sun }}=\alpha_{\text {wall }} * A_{\text {wall }} * I_{\text {sun,wall }} \\
& I_{\text {sun,wall }}=I_{\text {beam,wall }}+\frac{1}{2} * I_{\text {glob }} * \text { albedo }+\frac{1}{2} * I_{\text {diff }}
\end{aligned}
$$

where,

$$
I_{\text {beam,wall }}=\left(I_{\text {glob }}-I_{\text {diff }}\right) * F_{\text {wall }}
$$

$F_{\text {wall }}$ is the weighted average of the projection factors of all opaque walls facing different orientations. The hourly values of these projections factors are pre-computed all along the year as function of the incidence angles (for the latitude considered) and are provided as inputs for the model. 
So, the massive wall heat balance is governed by the following equations :

$$
\begin{gathered}
\dot{Q}_{\text {out }}=\frac{t_{\text {out }}^{*}-t_{c, \text { wall }}}{R_{\text {out }}} \\
\dot{Q}_{\text {in }}=\frac{t_{c, \text { wall }}-t_{\text {surf } \text { in }}}{R_{\text {in }}-R_{\text {surf } \text { in }}}
\end{gathered}
$$

$\frac{d U}{d \tau}=\dot{Q}_{\text {wall }}+\dot{Q}_{\text {out }}$

$\Delta U_{\text {wall }}=\int_{\tau 1}^{\tau 2} \frac{d U}{d \tau}$ wall $d \tau$

$\Delta U_{\text {wall }}=C_{\text {wall }} *\left(t_{c, \text { wall }}-t_{c, \text { wall }, 1}\right)$

The indoor surface temperature is computed by means of a supplemental heat balance, taking into account the short wave solar radiation entering the zone through windows and reaching the indoor surface of the wall (Figure 5).

$$
\begin{aligned}
& \dot{Q}_{\text {surf }, \text { in }}=\frac{t_{\text {surf }, \text { in }}-t_{a, \text { in }}}{R_{\text {surf } \text { in }}} \\
& \dot{Q}_{\text {in }}+\dot{Q}_{r, \text { wall }}=\dot{Q}_{\text {surf , in }}
\end{aligned}
$$

To calculate this radiant heat flow, a simplified hypothesis is made: short wave solar heat gains are supposed to be distributed all over the indoor surfaces proportionally to their respective areas (eq. 30).

$$
\dot{Q}_{r, \text { wall }}=\frac{A_{\text {wall }}}{A_{\text {wall }, \text { tot }}} * \dot{Q}_{\text {sun, windows }}
$$

where $\dot{Q}_{\text {sun,windows }}$ is computed as follow :

$$
\dot{Q}_{\text {sun,windows }}=S F_{\text {windows }} * A_{\text {windows }} * I_{\text {sun, windows }}
$$

The solar radiation incident to each window is computed in the same way as for massive walls. 
In the case of an "adiabatic wall" (floor, ceiling or party walls; Figure 2), the two-port network can be reduced to a simple branch composed of one resistance and one capacity. The same method is applied to compute solar heat gains reaching these walls.

Each light wall (as, for example, a window) is modelled with only one resistance, connected, on one side, to the indoor temperature node and, on the other side, to a node of corrected outdoor temperature, taking into account of sky radiation effect.

\subsubsection{Sensible Heat Gains}

Except for the solar radiation transmitted through the windows which is "injected" to the indoor surfaces, all sensible heat gains are injected to the indoor node (Figure 2) through the sensible heat balance of equation 8 . They include three contributions :

- sensible heat generated by electrical devices (lighting and appliances),

- sensible heat generated by occupants (function of the metabolic rate),

- sensible heat generated or absorbed by heating or cooling terminal units.

This give :

$\dot{Q}_{s, \text { in }}=\dot{Q}_{s, o c c}+\dot{W}_{\text {light }}+\dot{W}_{\text {appl }}+\dot{Q}_{s, \text { heating }}-\dot{Q}_{s, \text { cooling }}$

where $\dot{Q}_{s, \text { heating }}$ and $\dot{Q}_{s, \text { cooling }}$ are output variables of the terminal units models.

\subsubsection{Ventilation, infiltration and exfiltration sensible enthalpy flow rates}

The air leaving the zone (through ventilation exhaust and/or through exfiltration) is supposed to be at indoor temperature (due to a perfect "mixing" inside the zone). Ventilation air temperature is given as an output of the HVAC system model, while infiltrated air is at outdoor temperature.

Supply and exhaust state variables are used to define the CO2 (eq. 2), sensible enthalpy (eq. 33) and water (eq. 16) flow rates carried by the ventilation and infiltration/exfiltration:

$\dot{H}_{s, \text { vent }}=\dot{M}_{a, \text { ex, sup plyduct }} * c_{p, a} * t_{a, \text { ex sup plyduct }}-\dot{M}_{a, \text { su, returnduct }} * c_{p, a} * t_{a, \text { in }}$ 


$$
\dot{H}_{s, \text { inf }}=\dot{M}_{a, \text { inf }} * c_{p, a} * t_{\text {out }}-\dot{M}_{a, \text { exfiltr }} * c_{p, a} * t_{a, \text { in }}
$$

\subsubsection{Validation}

The thermal aspects of this simple dynamic building zone model have been validated (Bertagnolio et al., 2008) through analytical tests, empirical tests and through BESTEST comparative procedure (Judkoff and Neymark, 1995).

\subsection{HVAC System Model}

The building zone model presented here above can be easily connected to a complete "typical" HVAC system model, including, for example, a Constant Air Volume (CAV) Air Handing Unit (AHU), some local heating and/or cooling Terminal Units and a heating and cooling plant.

The system model actually available includes most of the classical HVAC components currently used (fans, air-to-air static recovery systems, coils, fan coils, pumps...).

Considering that the building model is a mono-zone model, most of components (AHUs, TUs, pumps,...) are aggregated into "global" components. The different locations of the terminal units and of the air diffusers are not yet considered.

Two different modelling levels are distinguished for the HVAC system (André et al., 2006b; Lebrun et al., 2006a):

- So-called "mother" ("first principle", or "mechanistic") models, containing all the (present) understanding of the physical phenomena, are used as references;

- So-called "daughter" ("simplified" and very often polynomial) model, generated with help of the help of the previous ones, are preferred to simulate large system on long time periods.

"Mother" models are preferred in some other domains of use, as, for instance, to support experimental work (design of the experiment and analysis of experimental results) or to characterize some specific equipment. "Daughter" models only are used in Benchmark. 


\subsubsection{Air Handling Unit}

The AHU considered may include a return fan, a return filter, a recovery system, a supply filter, a preheating coil, an adiabatic humidifier, a cooling coil, a post heating coil, a main fan and a steam humidifier (Figure 6). Of course, these components are usually not included all together (for example, both adiabatic and steam humidifiers don't have to be selected at same time).

In "Benchmark", the CAV AHU is supposed to provide a constant hygienic flow rate to the zone and to ensure humidity control (by humidification and/or dehumidification). Temperature control is then ensured by terminal units, as described hereafter.

\subsubsection{Fans}

The different pressure drops of the components are taken into account to compute the fans consumptions and the corresponding air heating-up.

The equations related to the return (or extraction) fan give, for instance:

$$
\dot{W}_{\text {returnfan }}=\dot{V}_{\text {returnfan }} * \frac{\Delta P_{\text {returnfan }}}{\varepsilon_{\text {s, returnfan }}}
$$

where,

$$
\Delta P_{\text {returnfan }}=\Delta P_{\text {returnduct }}+\Delta P_{\text {returnfilter }}+\Delta P_{\text {returneconomizer }}+\Delta P_{\text {returnre cov ery }}
$$

and,

$$
t_{a, \text { ex,returnfan }}=t_{a, \text { su, returnfan }}+\frac{\dot{W}_{\text {returnfan }}}{\dot{C}_{a, \text { returnfan }}}
$$

Similar equations are used to model the main supply fan.

\subsubsection{Heating Coils}

Heating coils are simulated by using a simplified $\varepsilon$-NTU model. In the classical $\varepsilon$-NTU model, the simultaneous calculations of air and water evolutions would consume more 
computational time. The simplification proposed here consists in not taking into account what happens on the water side; the heating coil is characterized by its air-side effectiveness only. When the control valve is fully open and for a constant air flow rate, the air-side effectiveness is expressed as:

$$
\varepsilon_{\text {a,heatingcoil }}=\varepsilon_{\text {heatingcoil }} * \frac{\dot{C}_{\min }}{\dot{C}_{a}}
$$

For a constant air flow rate, the maximal air exhaust temperature $t_{a, e x, \text { heatingcoil,max }}$ is supposed to be reached when the valve is fully open:

$$
t_{a, \text { ex, heatingcoil,max }}=t_{a, \text { su, heatingcoil }}+\varepsilon_{a, \text { heatingcoil }} *\left(t_{w, \text { su, heatingcoil }}-t_{a, \text { su, heatingcoil }}\right)
$$

The control variable is then used to compute the required exhaust temperature $t_{a, \text { ex, heatingcoil }}$ :

$$
t_{a, \text { ex heatingcoil }}=t_{a, \text { su, heatingcoil }}+X_{\text {heatingcoil }} *\left(t_{a, \text { ex, heatingcoil,max }}-t_{a, \text { su, heatingcoil }}\right)
$$

where $\mathrm{X}$ is the control variable (cf. $\S 3.3 .6)$.

The heating power actually provided by the coil is then computed:

$$
\dot{Q}_{\text {heatingcoil }}=\dot{C}_{a, \text { heatingcoil }} *\left(t_{a, \text { ex , heatingcoil }}-t_{a, \text { su, heatingcoil }}\right)
$$

This simplification allows to avoid the computation of the thermal exchange on water side. Only the characteristics of the coil in nominal regime are required to compute the air-side effectiveness.

\subsubsection{Cooling Coil}

Lemort et al. (2008) have used the same approach to build a simplified cooling coil model. They propose to do as if the cooling coil exhaust air temperature was controlled by its contact temperature (in place of the refrigerant flow rate). This control is described by equation 41 .

The exhaust air temperature is first compared to its set point. The control variable (comprised between 0 and 1) is then used to adjust the contact temperature (cf. §3.3.6).

$$
t_{c, \text { coil }}=t_{a, \text { su,coil }}-X_{\text {coil, control. }}\left(t_{a, \text { su,coil }}-t_{c, \text { coil, min }}\right)
$$


For given supply air temperature, contact effectiveness and contact temperature, the exhaust air temperature can be defined as follows:

$$
t_{a, e x, c o i l}=t_{a, s u, c o i l}-\varepsilon_{c, c o i l} \cdot\left(t_{a, s u, c o i l}-t_{c, \text { coil }}\right)
$$

The coil contact effectiveness is defined by the equation 43 .

$$
\mathcal{E}_{c, \text { coil }, \text { wet }}=1-\exp \left(-N T U_{c, \text { coil wet }}\right)
$$

with

$N T U_{c, \text { coil wet }}=\frac{1}{R_{a, \text { coil }} . \dot{C}_{a, \text { coil }}}$

This means that (as $\mathrm{R}_{\mathrm{a}}$ and $\dot{C}_{a}$ ), the contact effectiveness is only depending on the air flow rate. The exhaust air humidity is determined by equation 45 .

$$
w_{e x, c o i l}=w_{s u, c o i l}-\operatorname{MAX}\left(0, \varepsilon_{c, \text { coil }} .\left(w_{s u, c o i l}-w_{c, \text { coil }, \text { wet }}\right)\right)
$$

Once the exhaust air temperature and humidity are known, the sensible and latent heat outputs of the coil can be calculated.

The minimal value of the contact temperature (corresponding to the full opening of the control valve) must be determined as a function of both supply temperatures: the temperature of the refrigerant and the (dry bulb or wet bulb) temperature of the air (according to the regime :dry or wet):

$$
\begin{aligned}
& t_{c, \text { coil }, \text { min, }, d r y}=t_{a, s u, c o i l}-\frac{\varepsilon_{a, c o i l, d r y}}{\mathcal{E}_{c, c o i l}} .\left(t_{a, s u, c o i l}-t_{r, s u, c o i l}\right) \\
& t_{c, \text { coil }, \text { min }, \text { wet }}=t_{w b, s u, \text { coil }}-\frac{\mathcal{E}_{a, c o i l, w e t}}{\mathcal{E}_{c, \text { coil }}} .\left(t_{w b, s u, \text { coil }}-t_{r, \text { su, coil }}\right)
\end{aligned}
$$

In these equations, $\varepsilon_{a, \text { coil,dry }}$ and $\varepsilon_{a, c o i l, w e t}$ are the "air-side" effectiveness's, defined in dry and wet regimes respectively.

In each regime, the "air side" effectiveness is related to the actual coil effectiveness:

$$
\varepsilon_{a, \text { coil dry }}=\varepsilon_{\text {coil, dry }} \cdot \frac{\dot{C}_{\min , \text { coil,dry }}}{\dot{C}_{a, d r y}}
$$


$\varepsilon_{a, \text { coil,wet }}=\varepsilon_{\text {coil,wet }} \cdot \frac{\dot{C}_{\text {min }, \text { coil, wet }}}{\dot{C}_{a, f}}$

with,

$\dot{C}_{a, f}=\dot{M}_{a, \text { coil }} * c_{p, a, f, \text { coil }}$

The fictitious specific heat, $\mathrm{c}_{\mathrm{p}, \mathrm{af}}$ is defined by the equation 51 (Lebrun et al., 1990).

$c_{p, a, f, c o i l}=\frac{h_{a, s u, c o i l}-h_{a, e x, c o i l, w e t}}{t_{w b, s u, c o i l}-t_{w b, e x, \text { coil }, w e t}}$

These effectiveness's are defined with the valve fully open. If the air flow rate is varying, its effect has to be pre-identified with the help of the reference model.

The coil is supposed to work in dry regime, if the dew point temperature at cooling coil supply is lower than the minimum contact temperature. If not, it is supposed to be in wet regime:

If $t_{d p, s u, c o i l}<t_{c, c o i l, \text { min, wet }}, t_{c, c o i l, \text { min }}=t_{c, \text { coil }, \text { min }, d r y}$

If $t_{d p, s u, c o i l}>t_{c, \text { coil,min, wet }}, t_{c, \text { coil }, \text { min }}=t_{c, \text { coil }, \text { min, wet }}$

Lemort et al. (2008) have shown that the agreement between results of both reference and simplified models is very good. A comparative test between the reference and the simplified models proofs that the simplified model can be used without any significant loss of accuracy on the cooling load calculation. Moreover the calculation time dramatically reduced and no numerical instability is encountered.

\subsubsection{Humidifiers}

Both adiabatic and steam humidification are modelled in the present simulation tool.

Adiabatic humidification is supposed to be controlled by means of the preheating coil and is modelled by the following equations:

$$
\begin{aligned}
& w_{\text {ex,adiabhum }}=w_{\text {su,adiabhum }}+\varepsilon_{\text {adiabhum }} *\left(w_{s, \text { twb,adiabhum }}-w_{\text {su,adiabhum }}\right) \\
& t_{a, \text { ex,adiabhum }}=t_{a, \text { su,adiabhum }}+\varepsilon_{\text {adiabhum }} *\left(t_{w b, \text { su,adiabhum }}-t_{a, \text { su,adiabhum }}\right)
\end{aligned}
$$


Steam humidification is modelled by means of water and energy balances:

$$
\begin{aligned}
& w_{\text {ex,steamhum }}=w_{\text {su,steamhum }}+\frac{\dot{M}_{\text {steam }, \text { su,steamhum }}}{\dot{M}_{a, \text { steamhum }}} \\
& h_{a, \text { ex steamhum }}=w_{a, \text { su,steamhum }}+\frac{\dot{M}_{\text {steam,su,steamhum }}}{\dot{M}_{a, \text { steamhum }}} * h_{\text {steam }, \text { su,steamhum }}
\end{aligned}
$$

The exhaust air humidity ratio is then calculated by using the following control law :

$$
w_{\text {ex, steamhum }}=w_{\text {ex,steamhum }, 0}+X_{\text {steamhum }} * \Delta w_{\text {steamhum, max }}
$$

With $\mathrm{X}_{\text {steamhum }}$ as control variable (see hereafter)

\subsubsection{Terminal Units}

In Benchmark, room sensible heating and cooling are ensured by a classical fan coil unit.

In first and simple approach, this unit is characterized by its heat transfer coefficient only. The fan electrical power is defined as a percentage of the nominal heating/cooling power. The main outputs of this model are the heating/cooling power actually delivered and the related fan consumption.

In heating mode, for example, the heating power delivered by the fan coil is defined as follow:

$\dot{Q}_{\text {heating, } F C U}=X_{\text {heating, } F C U} * K_{\text {heating, } F C U} *\left(t_{w, \text { su, heating, } F C U}-t_{a, \text { in }}\right)$

$K_{\text {heating, } F C U}$ is the equivalent heat transfer coefficient of the fan coil unit:

$$
K_{\text {heating }, F C U}=\varepsilon^{*} \dot{C}_{\min }
$$

This term is defined for the nominal water flow rate (valve fully open) and for the fan rotation speed considered (usually selected by the occupant). $X_{\text {heating, } F C U}$ is the control variable (this control is supposed to consist in a tuning of the water flow rate).

The cooling power is defined in the same way. Possible water condensation inside the fan coil is not yet taken into account in Benchmark, but it could be easily included by using a model similar to the one used for the cooling coil of the Air Handling Unit. 


\subsubsection{Hot and cold water distributions}

Water networks are modelled in such a way to take both pressure drops and heat exchanges into account.

In Benchmark, a first approximation consists in characterizing each water distribution network with only one equivalent thermal efficiency.

Equivalent nominal water flow rates are defined on the basis of nominal heating and cooling powers and of nominal temperature variations. For the hot water distribution, for example:

$$
\dot{M}_{w, \text { hotwaterdistr }}=\frac{\dot{Q}_{\text {heatingplant }, n}}{c_{p, w} * \Delta t_{w, \text { heatingplant }, n}}
$$

The so-defined "primary" water flow rate is kept constant in the simulation.

Both heating-up through the pump and heat exchanges along the distribution network are taken into account. For hot water distribution, for example, this gives:

$$
\begin{aligned}
& t_{w, \text { ex, hotwaterdistr }}=t_{w, \text { su,hotwaterdist }}+\left(\frac{\dot{W}_{\text {sh,hotwaterpump }}-\dot{Q}_{\text {hotwaterdistr,loss }}}{\dot{M}_{w, \text { hotwaterdistr }, n} * c_{p, w}}\right) \\
& \dot{Q}_{\text {hotwaterdistr, loss }}=\left(1-\eta_{\text {hotwaterdistr }}\right) * \dot{Q}_{\text {heatingdemand }}
\end{aligned}
$$

The primary water pump consumption is defined as follows:

$$
\begin{aligned}
& \dot{W}_{\text {sh,hotwaterpump }}=\dot{M}_{w, \text { hotwaterdistr, } n} * \frac{\Delta P_{w, \text { hotwaterdistr }}}{\rho_{w}^{*} \varepsilon_{s, \text { sh,hotwaterpump }}} \\
& \dot{W}_{\text {hotwaterpump }}=\frac{\dot{W}_{\text {sh,hotwaterpump }}}{\eta_{\text {hotwaterpump }}}
\end{aligned}
$$

Similar equations are used to model the chilled water network and its pump.

\subsubsection{Heat Production}

In the present version of Benchmark, heat is supposed to be produced by a classical fuel-oil boiler with ON/OFF control. 
The "daughter" boiler model used here is derived from the reference ("mother") model developed by Bourdouxhe et al. in the ASHRAE HVAC1 Toolkit (1999).

In the mother model, the boiler is represented by an assembly of a supposed to be adiabatic combustion chamber and two (gas-water and water-environment) heat exchangers (Figure 7). At constant water supply temperature, the fuel oil boiler submitted to ON/OFF control has a very linear behaviour as shown in Figure 8. This suggests that a double linear correlation can be used as simplified model. Consumed power is plotted as function of useful power and a linear fit is made on this curve.

Applying the same methodology to the same boiler for different values of water supply temperature (e.g. from $50^{\circ} \mathrm{C}$ to $80^{\circ} \mathrm{C}$ ), and using reduced variables, the following correlation is established (eq. 66).

$$
\begin{aligned}
& \dot{q}_{u, \text { red }}=\frac{\dot{Q}_{u}}{\dot{Q}_{u, n, \text { on }}} \\
& \dot{q}_{c, \text { red }}=\frac{\dot{Q}_{c}}{\dot{Q}_{c, n, o n}} \\
& \dot{q}_{c, \text { red }}=C_{0}+C_{1} * \dot{q}_{u, \text { red }}
\end{aligned}
$$

The values of $\mathrm{C}_{0}$ and $\mathrm{C}_{1}$ can be correlated with the water supply temperature as follows:

$$
\begin{aligned}
& C_{0}=C_{0,0}+C_{0,1} * t_{w, \text { su,boiler }} \\
& C_{1}=C_{1,0}+C_{1,1} * t_{w, \text { su,boiler }}
\end{aligned}
$$

If there is no mixing valve or if it's fully open, the boiler water supply temperature corresponds to the heating plant return water temperature:

$$
t_{w, \text { return, heatingplant }}=t_{w, \text { ex,hotwaterdistr }}-\frac{\dot{Q}_{\text {heatingdemand }}}{\dot{M}_{w, \text { hotwaterdistr }} * c_{p, w}}
$$

In Benchmark, the boiler is only submitted to weather control: the exhaust water temperature set point is fixed according to the outdoor temperature. 
Of course, it may occur that this set point stay above the maximal temperature achievable; in such case, the boiler is running in full load.

\subsubsection{Cold Production}

For the chiller, various simplified "daughter" models are available (Lebrun et al., 2006a). The simplest one consists in expressing the chiller "capacity" (full load cooling power) and the corresponding electrical consumption as polynomial functions of two independent variables:

1) the temperature of the secondary fluid supplying (or leaving) the evaporator

2) the temperature of the secondary fluid supplying the condenser (Figures 9).

The part load regime can be described with the help of Heating, Cooling and Electrical load factors (eq. 70, 71 and 72):

$$
\begin{aligned}
& H L F=\frac{\dot{Q}_{c d}}{\dot{Q}_{c d, \text { max }}} \\
& C L F=\frac{\dot{Q}_{e v}}{\dot{Q}_{e v, \text { max }}} \\
& E L F=\frac{\dot{W}_{e l}}{\dot{W}_{e l, \text { max }}}
\end{aligned}
$$

Simple polynomial laws can also be used to correlate electrical and cooling load factors to each other (Figure 10).

A better, but still very simple, approach consists in using the evaporation and condensation temperatures (in place of the secondary fluid temperatures) in the two first polynomial laws (which then concern the compressor and the refrigeration cycle only). Separate semiisothermal heat exchanger models can then be used to deal with the evaporator and with the condenser. The definitions of the part load factors stay the same as for the first model. This is the approach preferred in Benchmark.

In ideal control conditions, the simulation will determine the chilled water supply temperatures "required" by both air handling and terminal units. These temperatures will be 
generated by the (real or fictitious) proportional controls of both units. The minimum between these two temperatures will become the set point of the chiller control.

Of course, it may occur that this set point stay below the minimal temperature achievable, in such case, the chiller is running in full load.

\subsubsection{HVAC system control}

When having to deal with a complex system simulation, a good engineer approach consists in starting with idealistic hypotheses and going progressively to more realism, according to what is looked for. Ideal control allows using simpler simulation models, gives easier access to benchmarks and indicates clearly the maximal performances that could be reached.

A simple proportional control laws is used for each component, with a non dimensional control variable $X_{\text {control, }}$, varying between 0 and 1 in proportion of the difference observed between the set point and the controlled variable:

$$
X_{\text {control }}=\operatorname{MIN}\left(1, \operatorname{MAX}\left(0, C_{\text {control }} *\left(t_{\text {sepoint } t}-t\right)\right)\right)
$$

The control "gain", $C_{\text {control }}$, is arbitrarily fixed as a realistic compromise between accuracy and robustness.

\subsection{Interface and Implementation}

In Benchmark, all the parameters asked to the user have to be provided by means of control panels. A main control panel (Figure 11) is used to access the other ones. The "Building description" panel (Figure 12) is used to fix the geometry of the building, the characteristics of the envelope and the internal gains (occupancy, lighting and appliances). The "Air Handling Unit" panel (Figure 13) is used to select the main characteristics of this subsystem (existence of a mechanical ventilation, hygienic ventilation flow rate, type of humidification system, water nominal temperature regimes and nominal fan efficiencies). The temperature and humidity set points and the control laws can be modified in the "HVAC System Control" panel (Figure 14). 


\section{Example of Use}

\subsection{Building description}

The model presented here above is applied to an existing medium-size office building (around $26700 \mathrm{~m}^{2}$ of air-conditioned floor area), erected in Brussels at the end of the sixties (Lebrun et al., 2006b). The building is composed of three blocks, has a " $\mathrm{H}$ " shape (figure 15) and is North-South oriented. Eight storeys of the building include landscaped offices and meeting rooms and are occupied by about 1100 people, between 8 am and $18 \mathrm{pm}$. The five underground levels are dedicated to cars parking. The frontages of the lobby are made of single-glazed windows. The rest of building envelope is made of about 1000 double-glazed modules as shown in figure 15. The main characteristics of the envelope are given in table 1 . About 1000 four-pipes heating and cooling induction units are installed in the offices. The CAV Air Handling Units provide together a total of about $190000 \mathrm{~m}^{3} / \mathrm{h}$ of fresh air per hour, 75 hours per week, to the conditioned zones (from level 0 to 8 ). Vitiated air is rejected in the underground storeys to ensure ventilation of the parking. This ventilation flow rate corresponds to about 2.4 air renewals per hour. According to the outdoor weather conditions, the supplied air can be heated, adiabatically humidified, or cooled and dehumidified. Heat production is ensured by four fuel-oil boilers, giving together a nominal heating capacity of about $4 \mathrm{MW}$. Chilled water production is ensured by four water cooled chillers, coupled to two cooling towers, giving a total cooling capacity of about $2.1 \mathrm{MW}$.

Recorded monthly fuel consumptions are available from 1975 to 2005 and monthly records of electricity consumption are available from September 2004 to February 2006.

Classical thermal signature based on recorded data (2005) can be built by expressing the monthly average heating powers as function of the average outdoor temperature (Figure 16). The slope of this signature (about $42 \mathrm{~kW} / \mathrm{K}$ ), should correspond to the global heat transfer 
coefficient of the building. However, the interpretation of this curve stays quite difficult because of the very global data used and the poor correlation factor $\left(\mathrm{R}^{2}=0.6647\right)$.

Electricity signatures can also be built by expressing the monthly electrical power demand (2005) as function of the outdoor temperature. As shown in Figure 17, no significant correlation can be established between the two variables: the electricity consumption stays quite constant all along the year.

Such information is too limited to be directly used, but much more can be learned through the use of simulation model tuned on the available data.

\subsection{Use of "BENCHMARK"}

The software presented above is applied to the nine conditioned storeys of the building (from level 0 to 8), simulated as a unique zone. Parking zone is not considered in the study. The actual characteristics of the building envelope, the estimated internal generated gains, the actual occupancy schedules and temperature and humidity setpoints are entered in the software. The first approach consists in supposing that the studied building is coupled to the "typical" HVAC system described above. The performances of this system (pressure drops and HVAC components efficiencies) are estimated according to the standards prEN 13053 and 13773 (table 2). The constant hygienic ventilation flow rate is fixed to $45 \mathrm{~m}^{3} / \mathrm{h}$ of fresh air per hour and per occupant.

This first simulation gives the results plotted in Figure 18 and 19. To allow a fair comparison between measured and computed data, monthly fuel consumptions are here averaged on the 30 years of available data. This method tends to minimize the error due to the use of a typical set of weather data, based on averages carried out over thirty years of measurements, realized in Uccle (Belgium). For electricity consumption, the values of 2005 are used as reference. 
It appears that monthly computed and measured consumptions are very different. Mostly the fuel, but also the electricity consumptions are largely underestimated by the software. This suggests the existence of important energy savings potentials.

\subsection{Calibration}

In this second phase of the study, a more complete tool using the same bases has to be used. This second tool is very similar to the first one, but includes additional HVAC components models as induction unit, radiator, cooling ceiling models, etc. These additional components models will be described in further papers.

With more realistic hypotheses (much higher ventilation flow rate) and a description of the actual HVAC system (four-pipes induction units, no heat recovery system,...) and its performances and operating conditions, the software gives the results shown in Figure 20. The computed and measured monthly consumptions are now in fair agreement.

After this calibration, the tool can be used to disaggregate the electricity consumption and to identify the main energy consumers (Figure 21). This indicates that an important part of the electricity consumption is due to lighting and appliances. Fans and pumps are in charge of about $22 \%$ of the global electrical consumption, while chiller part is only of about $10 \%$.

Finally, some selected ECO's would be evaluated on economical and environmental bases. This second part of the work will be described in further papers.

\section{Advantages and limitations of equation solvers}

The presented model is implemented on an Engineering equation solver (Klein, 2008). This implementation ensures also a full transparency for the user and makes easier the continuous improvement and development of the tools. Indeed, model's equations are directly readable and easy to modify by any user (Figure 22). It is also very easy to develop additional HVAC components models and to connect them to the existing ones. Moreover, the present equation 
solver is very well adapted to solve differential equations systems as used to model the thermal behaviour of the building zone.

Of course, the use of an equation solver to solve complex equation systems implies longer computation time than other simulation softwares, but the continuous increase of computer performances tends to reduce this inconvenience. At present time, about 20 minutes are necessary to simulate a mono-zone building and its complete HVAC system (including AHU, terminal units and heat and cold production and distribution) hour by hour on one year with a classical computer equipped with a $2.00 \mathrm{GHz}$ processor.

\section{Conclusion}

Fairly detailed and realistic simulations are possible today in the field of buildings and HVAC. The use of an equation solver makes the models fully transparent and easy to improve whenever required.

HVAC equipment modelling can be performed at different levels: The most simplified models with very few parameters can be of great help in the first stage of an energy audit. The "Benchmark" tool presented in this paper is an example of such simulation model. It allows the auditor to get a first impression about energy saving potentials.

Then, a calibrated but still simplified simulation tool is used to disaggregate the electricity consumption and to allow a better interpretation of on site records.

Finally, more detailed and specific simulation tools should be used to allow a safe identification and an assessment of the most promising retrofit opportunities. More detailed and complete simulation tools will be presented in further papers. 


\section{ACKNOWLEDGMENTS}

This work is performed with the support of the Walloon Region of Belgium and of Intelligent Energy Europe programme. The sole responsibility for the content of this document lies with the authors. It does not represent the opinion of the Community. The European Commission is not responsible for any use that may be made of the information contained therein.

\section{REFERENCES}

André P, Lebrun J, Adam C, Aparecida Silva C, Hannay J, Lemort V (2006). A contribution to the audit of an air-conditioning system : modelling, simulation and benchmarking. In: Proceedings of the $7^{\text {th }}$ International Conference on System Simulation in Buildings, Liège, Belgium.

André P, Lebrun J, Adam C, Georges B, Lemort V, Teodorese I (2006). From model validation to production of reference simulations : how to increase reliability and applicability of building and HVAC simulation models. In: Proceedings of the $7^{\text {th }}$ International Conference on System Simulation in Buildings, Liège, Belgium.

AuditAC (2007). AuditAC project : field benchmarking and market development for audit methods in air conditioning. AuditAC Final report. Intelligent Energy Europe programme.

Bertagnolio S, Masy G, Lebrun J, André P (2008). Building and HVAC System simulation with the help of an engineering equation solver. Paper presented at the Simbuild 2008 Conference, Berkeley, USA.

Bliss R (1961). Atmospheric radiation near the surface of the ground: a summary for engineers. Solar Energy. 5: 103-120. 
Bourdouxhe J-P, Grodent M, Lebrun J, Saavedran C (1999). ASHRAE HVAC1 Toolkit : A Toolkit for Primary System Energy Calculation. Atlanta: American Society of Heating, Refrigerating and Air-Conditioning Engineers, Inc.

European Standard prEN13053 (2003) Ventilation for buildings - Air handling units - Ratings and performance for units, components and sections.

European Standard prEN13779 (2007) Ventilation for non-residential buildings Performance requirements for ventilation and room-conditioning systems.

Fanger P (1970). Thermal Comfort - Analysis and Applications in Environmental Engineering. Copenhagen: Danish Technical Press.

Harmonac (2008). Harmonac project : Harmonizing Air Conditioning Inspection and Audit Procedures in the Tertiary Building Sector. Intelligent Energy Europe programme.

Jagpal R (2006). International Energy Agency - Energy Conservation in Buildings and Community Systems Annex 34 : Computer Aided Evaluation of HVAC System Performance. Synthesis Report.

Judkoff R, Neymark J (1995). International Energy Agency - Building Energy Simulation Test (BESTEST) and Diagnostic Method. National Renewable Energy Laboratory, U.S. D.O.E. 
Klein SA (2008). EES: Engineering Equation Solver, User manual. F-chart software. Madison: University of Wisconsin-Madison, USA.

Klein SA, Beckman WA, Mitchell, JW, Duffie JA (2004). TRNSYS 16-a TraNsient System Simulation program, User manual. Solar Energy Laboratory. Madison: University of Wisconsin-Madison, USA.

Laret L (1980). Use of general models with a small number of parameters, Part 1: Theoritical analysis. In: Proceedings of Conference Clima 2000, Budapest, 263-276.

Lebrun J (1978). Etudes expérimentales des regimes transitoires en chambres climatiques. Ajustement des méthodes de calcul. Journées Bilan et Perspectives Génie Civil, INSA Lyon, France. (in French).

Lebrun J, Liebecq G (1988). International Energy Agency - Energy Conservation in Buildings and Community Systems Annex 10: Building HVAC System Simulation. Synthesis Report.

Lebrun J, Ding X, Eppe J-P, Wasacz M (1990). Cooling Coil Models to be used in Transient and/or Wet Regimes. Theoretical Analysis and Experimental Validation. In: Proceedings of the $3^{\text {rd }}$ International Conference on System Simulation in Buildings, Liège, Belgium.

Lebrun J, Wang S (1993). International Energy Agency - Energy Conservation in Buildings and Community Systems Annex 17: Building Energy Management Systems - Evaluation and Emulation Techniques. Synthesis Report. 
Lebrun J, André P, Aparecida Silva C, Hannay J, Lemort V, Teodorese V (2006). Simulation of HVAC systems : development and validation of simulation models and examples of practical applications. In: Proceedings of the Mercofrio 2006 Conference, Porto Alegre, Brazil.

Lebrun J, André P, Hannay J, Aparecida Silva C (2006). Example of audit of an air conditioning system. In: Proceedings of the Klimaforum Conference, Godovic, Slovenia.

Lemort V, Cuevas C, Lebrun J, Teodorese I (2008). Development of Simple Cooling Coil Models for Simulation of HVAC Systems. ASHRAE Transactions 114(1).

Masy G (2006). Dynamic Simulation on Simplified Building Models and Interaction with Heating Systems. In: Proceedings of the $7^{\text {th }}$ International Conference on System Simulation in Buildings, Liège, Belgium.

Visier, J.C., Jandon, M. 2004. International Energy Agency - Energy Conservation in Buildings and Community Systems Annex 40: Commissioning of Building HVAC Systems for Improved Energy Performances. Synthesis Report.

Woloszyn M (1999). Moisture-Energy-Airflow modelling of multizone buildings. PhD Dissertation. CETHIL Laboratory, INSA Lyon, France. 


\section{TABLES AND FIGURES}

Figure 1: Model Block Diagram

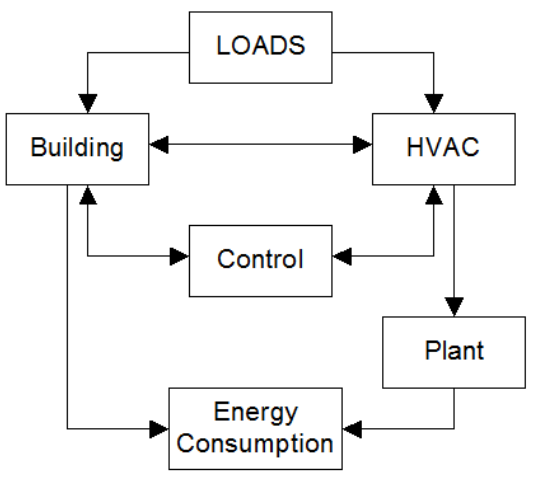

Figure 2: Dynamic Building Model Equivalent R-C network

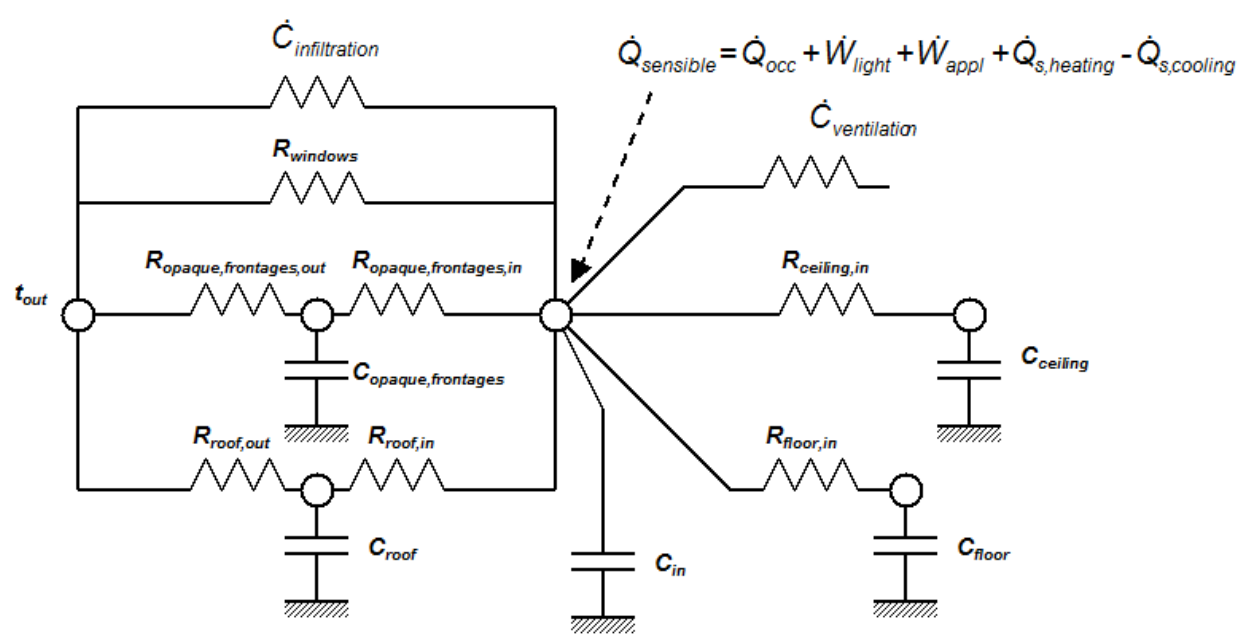

Figure 3: Massive wall two-port network

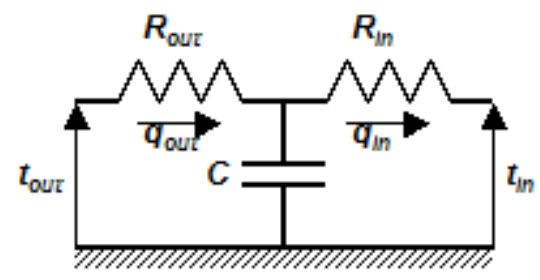


Figure 4: Corrected outdoor temperature

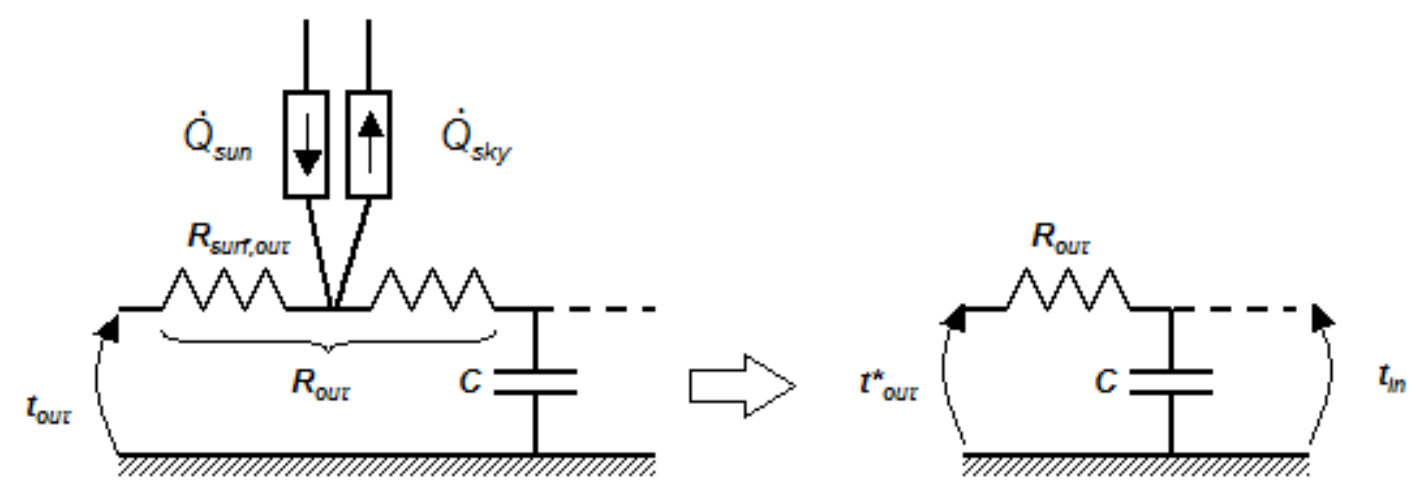

Figure 5: Injection of short wave radiation at indoor surface node of the walls

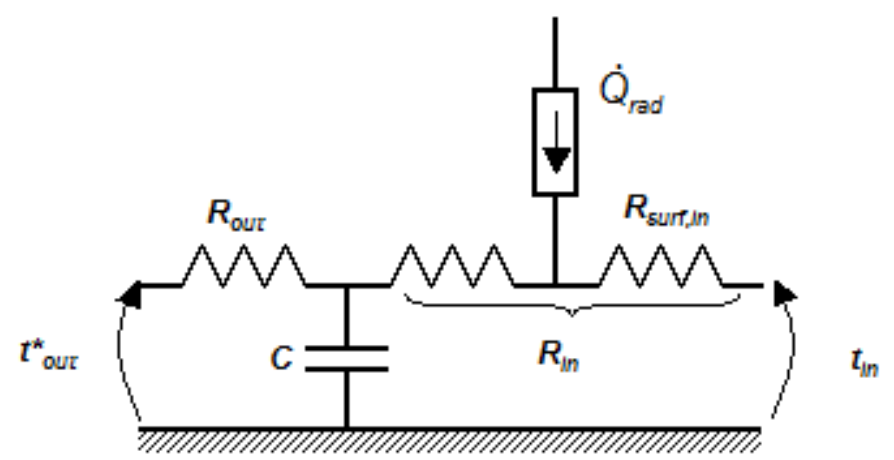

Figure 6: Double flux Air Handling Unit

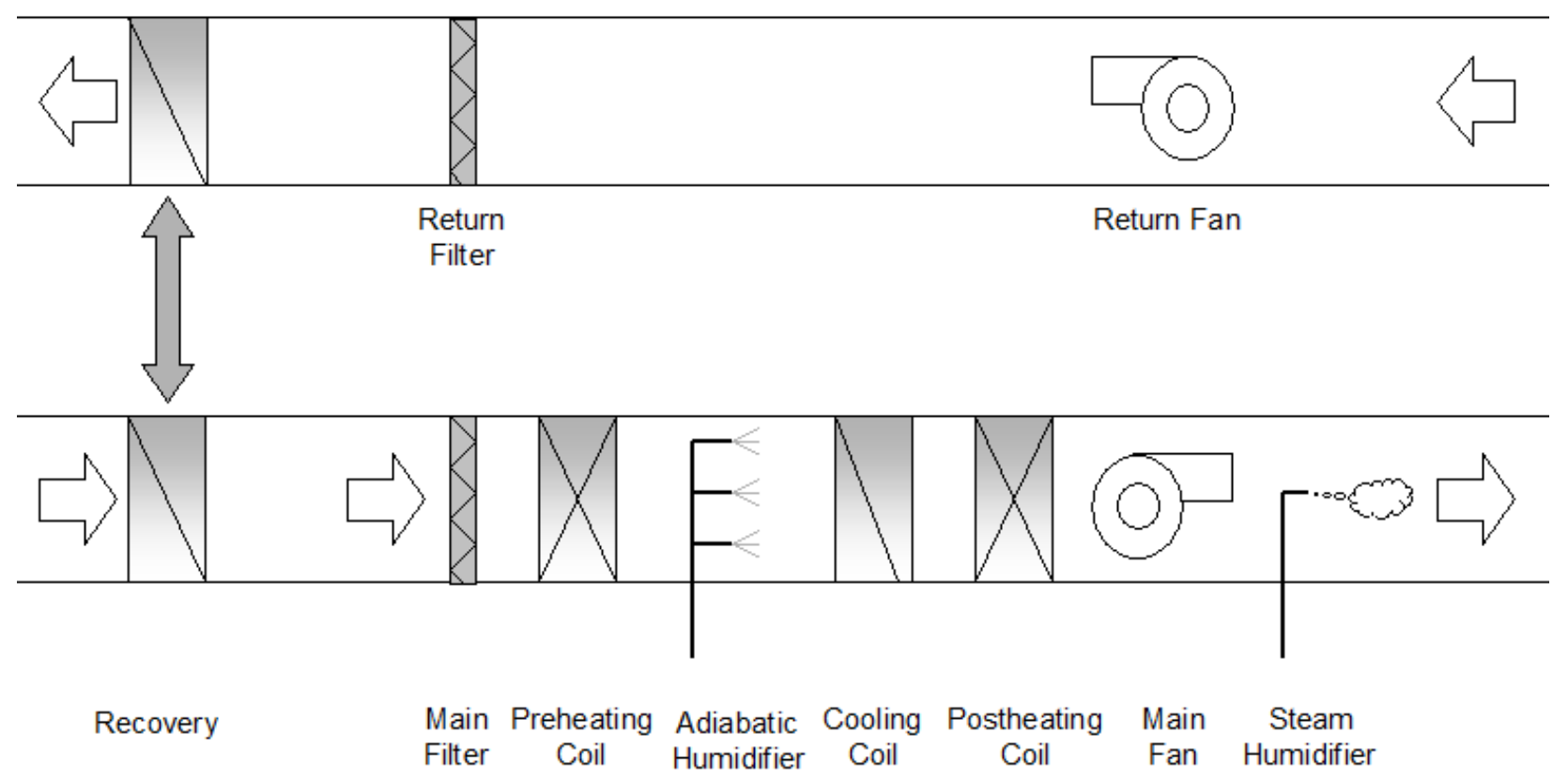


Figure 7: Boiler Model Components

\section{Boiler}

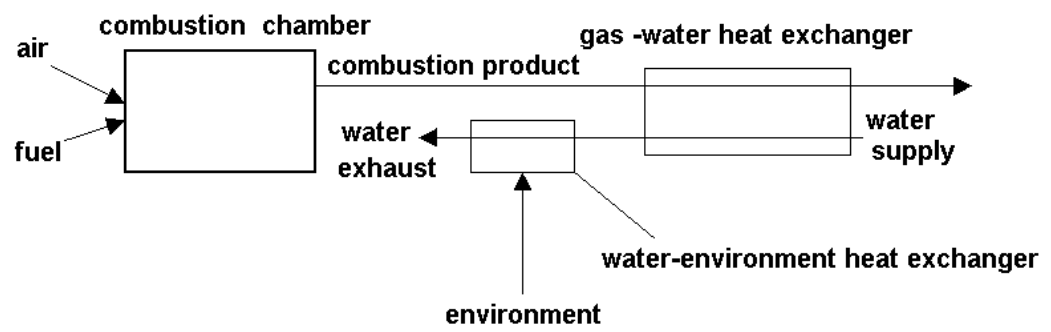

Figure 8: Boiler consumption as function of its useful thermal power at constant water supply temperature (ON/OFF control).

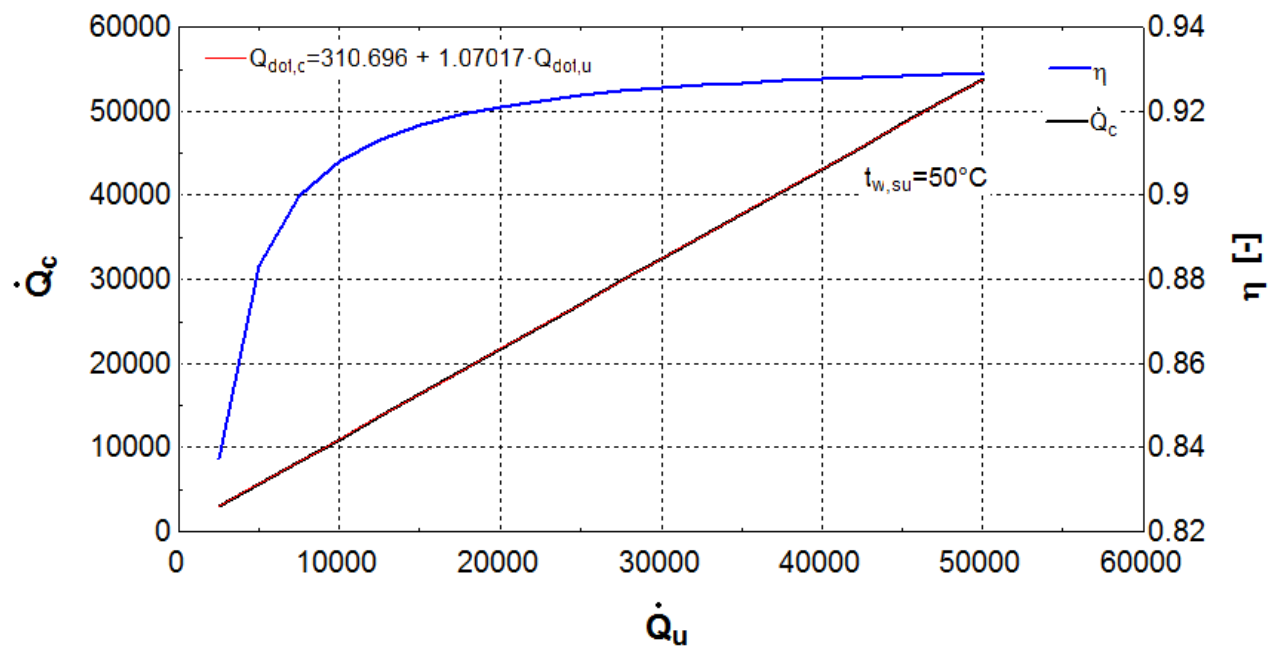

Figure 9: Cooling capacity as function of secondary fluids temperatures

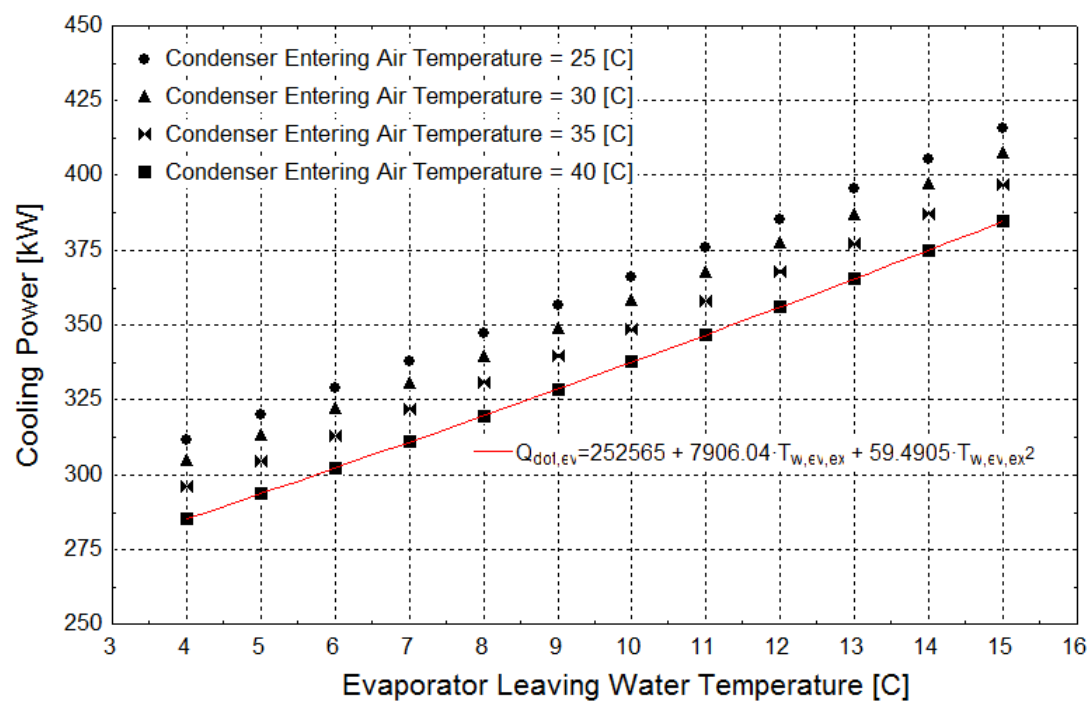


Figure 10: Possible relationship between electrical and thermal load factors

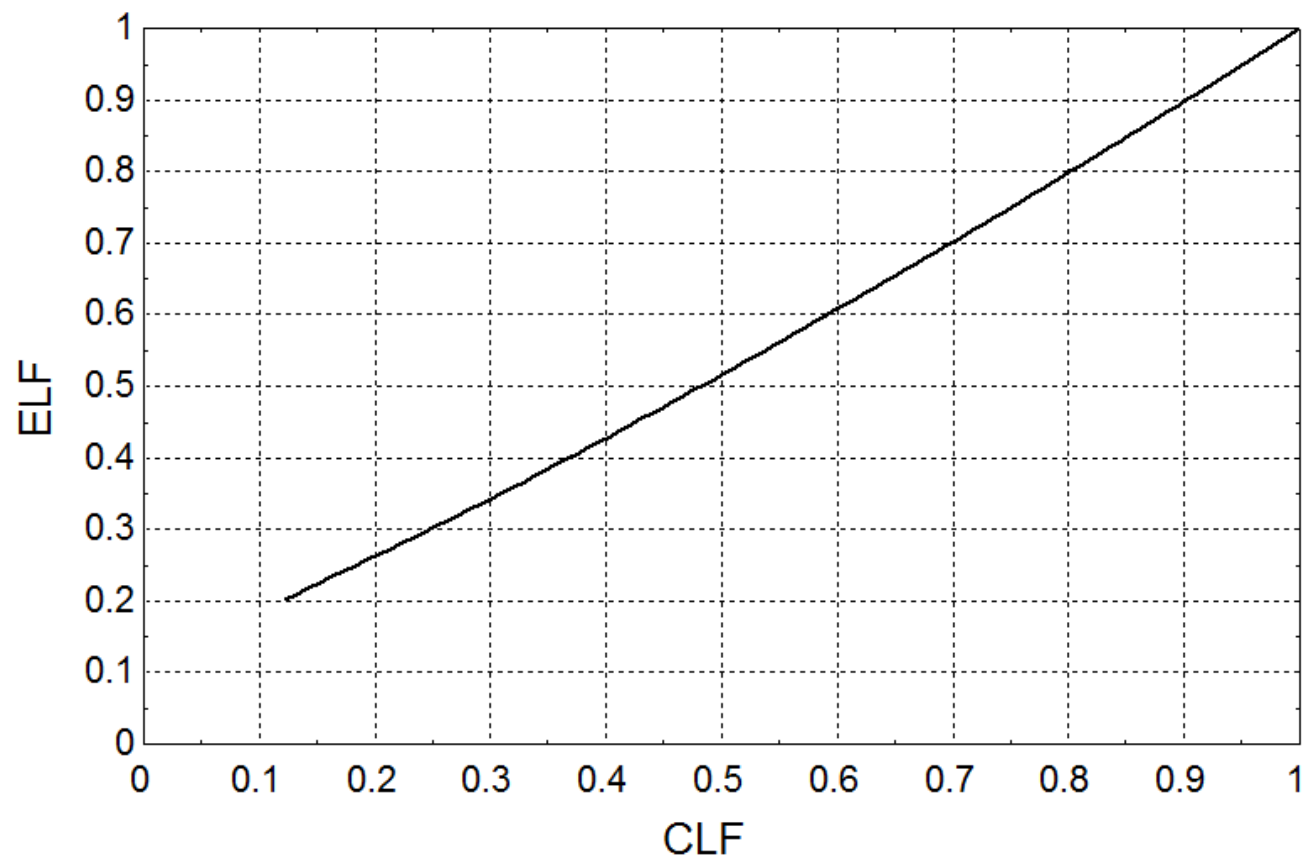

Figure 11: Main control panel

\section{HARMONAC}

BENCHMARK : Multi-storey building v1.1

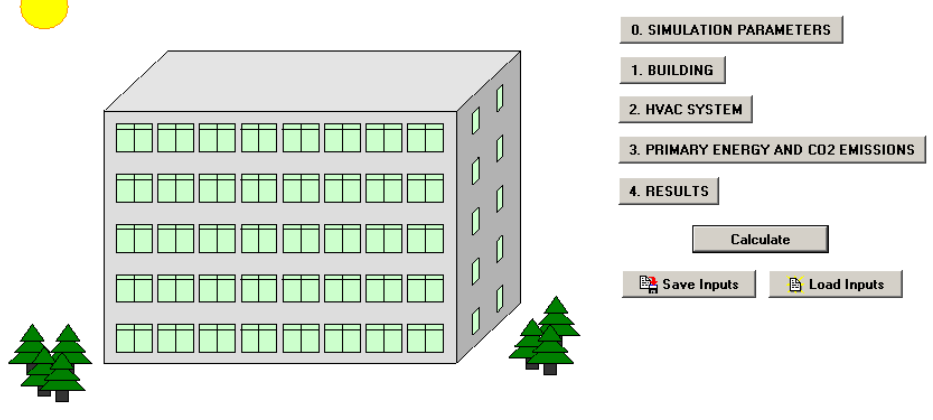


Figure 12: "Building description" control panel

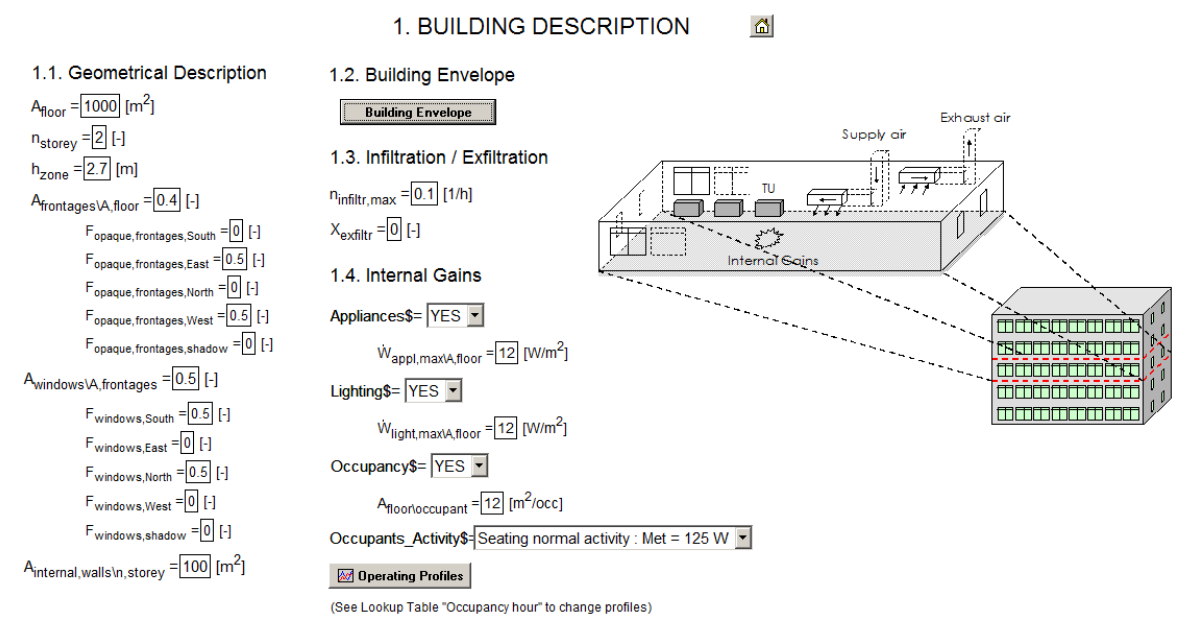

Figure 13: "Air Handling Unit" control panel

2.2. Air Handling Unit 通

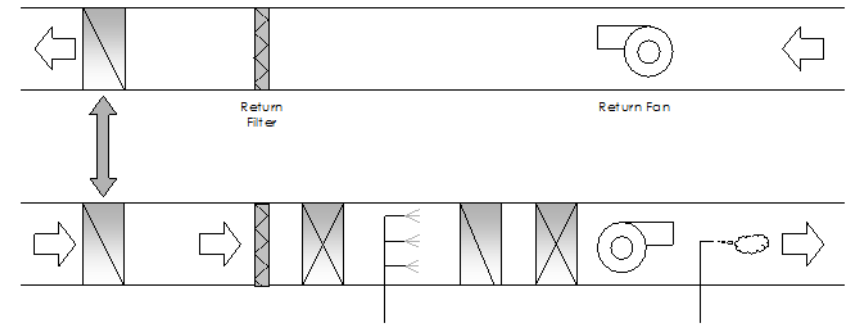

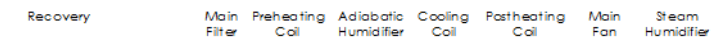

Exist_AHUS=Y YES

2.2.1. Air Extraction

Return_duct\$=YES

2.2.2. Air Supply

Supply_duct\$=YES $\square$

Humidification $\$=$ ADIABATIC

Dehumidification $\$=$ YES

$$
\begin{aligned}
& \text { 2.2.3. Sizing } \\
& \text { 2.2.3.1. Nominal (hygienic) Ventilation Rate } \\
& \mathrm{n}_{\mathrm{CAV}, \text { vollh, } \mathrm{n}}=1[\mathrm{vol} / \mathrm{h}] \\
& \text { 2.2.3.2. Nominal Water Temperatures } \\
& \mathrm{t}_{\mathrm{w}, \mathrm{su}, \mathrm{AHU}, \text { heating, } \mathrm{n}}=80[\mathrm{C}] \\
& \Delta \mathrm{t}_{\mathrm{w}, \mathrm{AHU}, \text { heating, } \mathrm{n}}=20[\mathrm{~K}] \\
& \mathrm{t}_{\mathrm{w}, \mathrm{su}, \mathrm{AHU}, \text { cooling, } \mathrm{n}}=7[\mathrm{C}] \\
& \Delta \mathrm{t}_{\mathrm{w}, \mathrm{AHU}, \text { cooling, } \mathrm{n}}=5[\mathrm{~K}]
\end{aligned}
$$

2.2.3.3. Nominal Effectivenesses

$\varepsilon_{\text {recovery, } \mathrm{n}}=0.8[-]$

$\varepsilon_{\text {adiabhum, } \mathrm{n}}=0.85$ [-]

$\varepsilon_{\mathrm{S}, \text { mainfan, } \mathrm{n}}=0.75[-]$

$\varepsilon_{\mathrm{s}, \text { returnfan } \mathrm{n}}=0.75[\mathrm{H}]$

$\eta_{\text {steamgenerator, } \mathrm{n}}=0.9[\mathrm{H}]$

2.2.3.4. Nominal Pressure Drops

Nominal Pressure Drops

2.2.3.5. Control 
Figure 14: "HVAC System Control" control panel

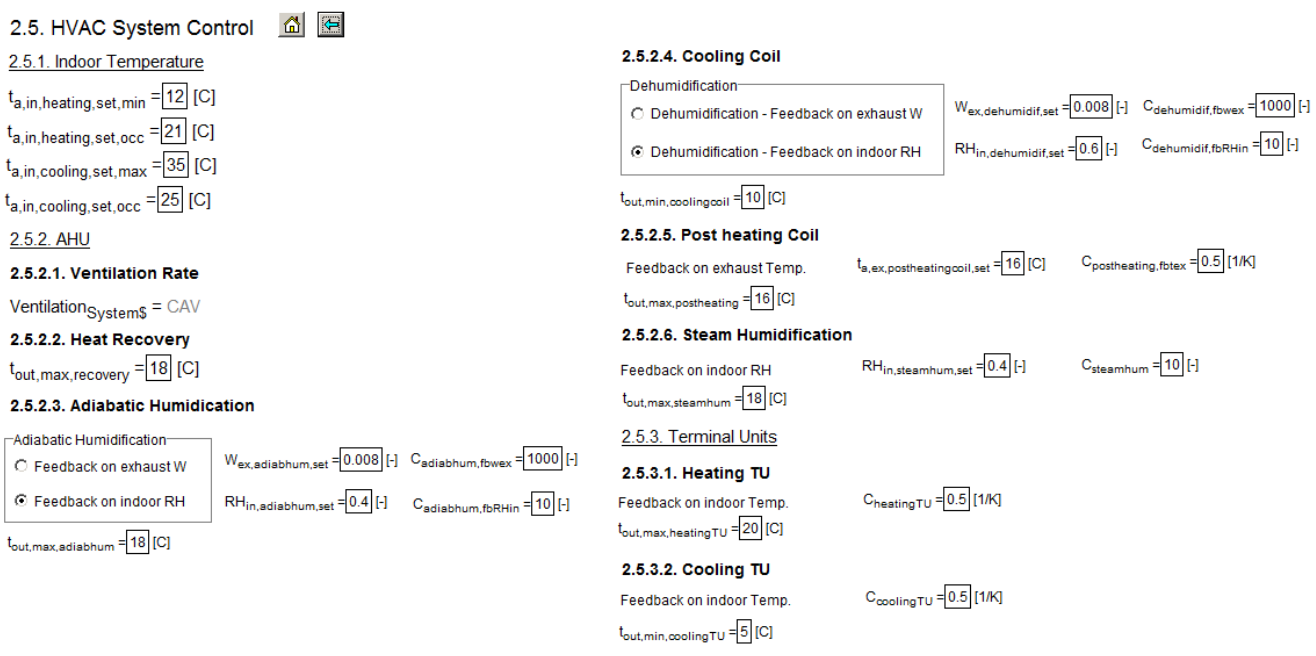

Figure 15: Case study building (left) and envelope module (right)
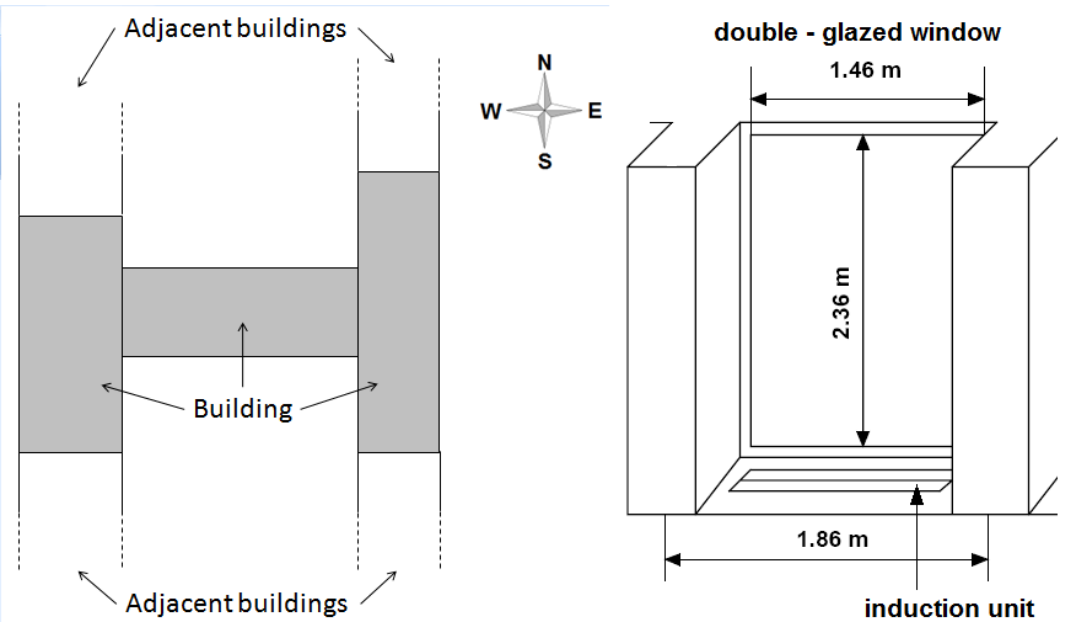

Figure 16 : Building Thermal Signature (2005)

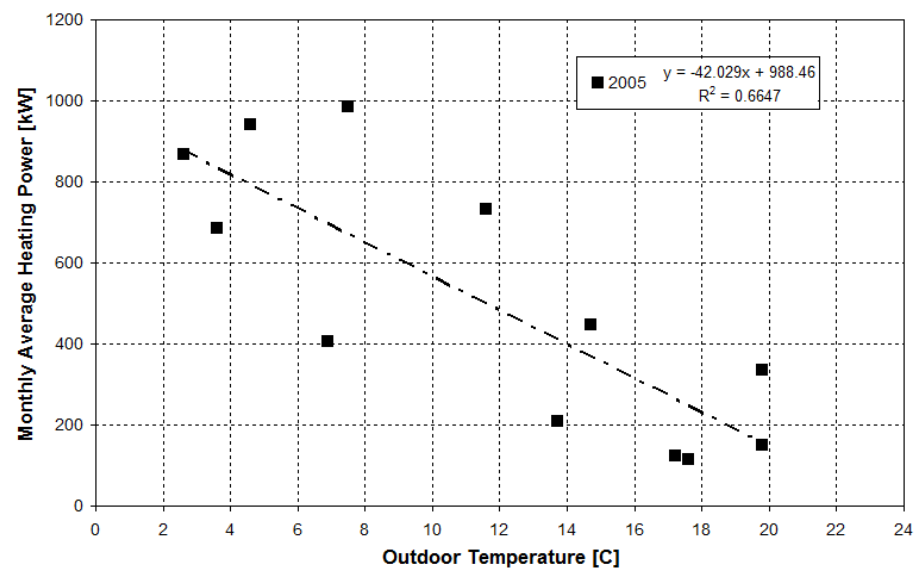


Figure 17: Building Electrical Signature

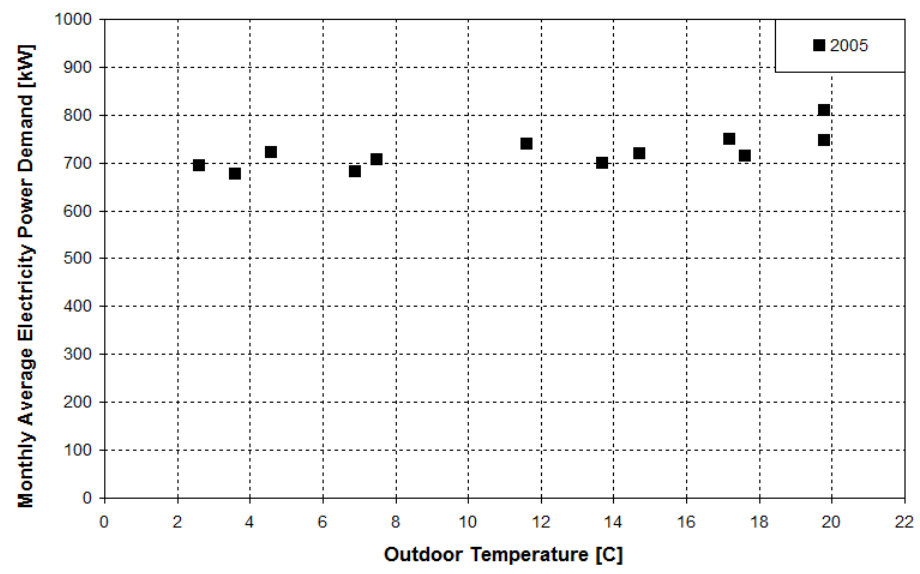

Figure 18: Measured and computed fuel consumptions (first run)

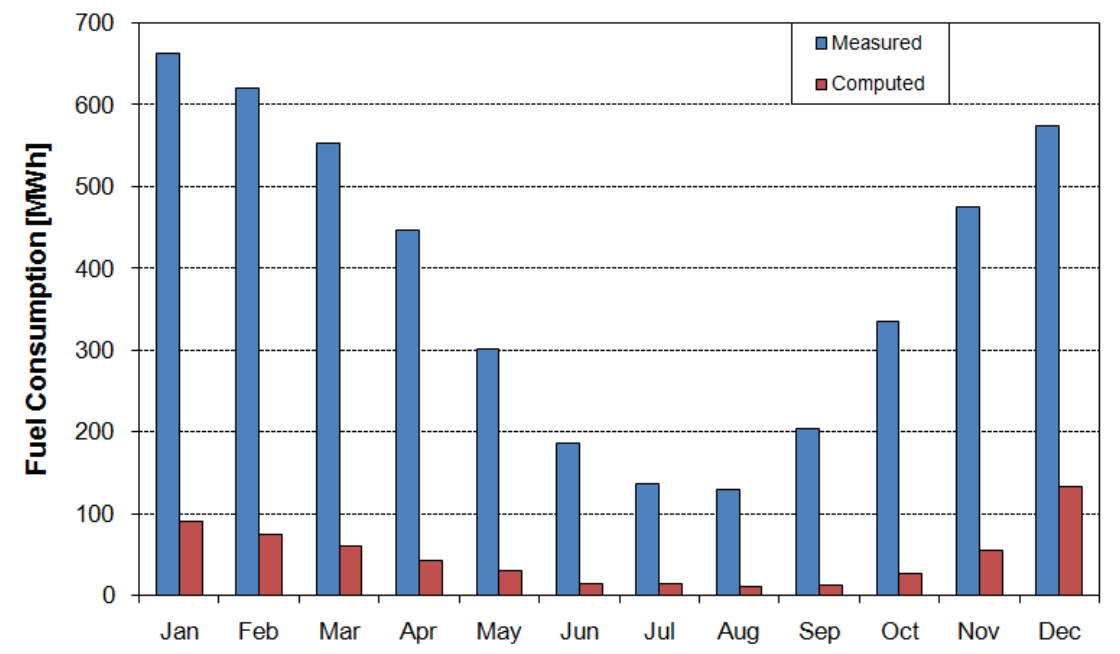

Figure 19: Measured and computed electricity consumptions (first run)

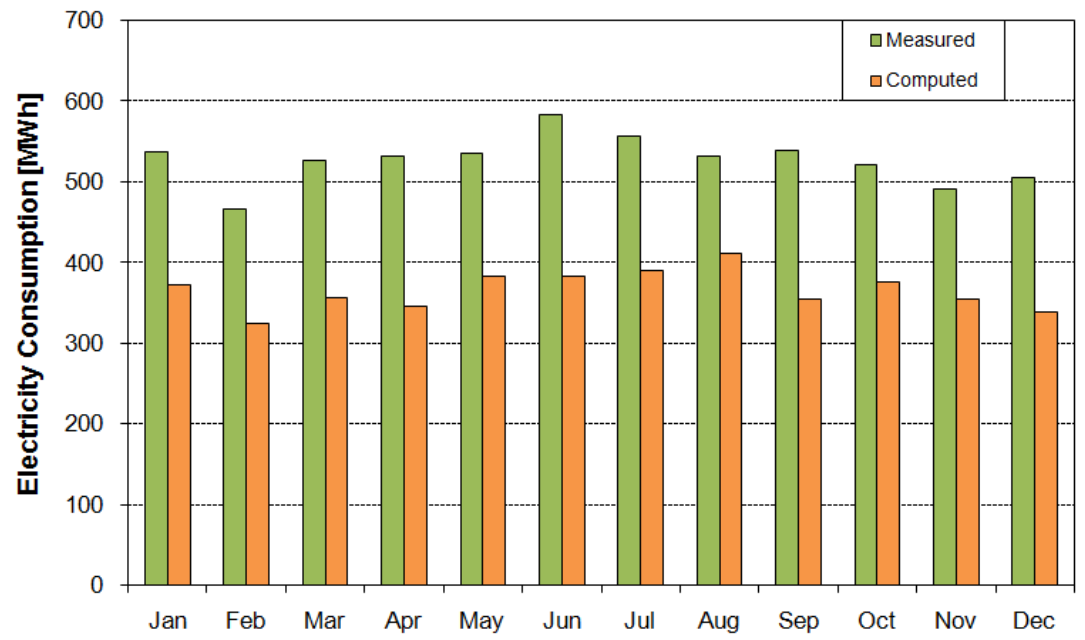


Figure 20 : Measured and computed fuel consumptions (after calibration)

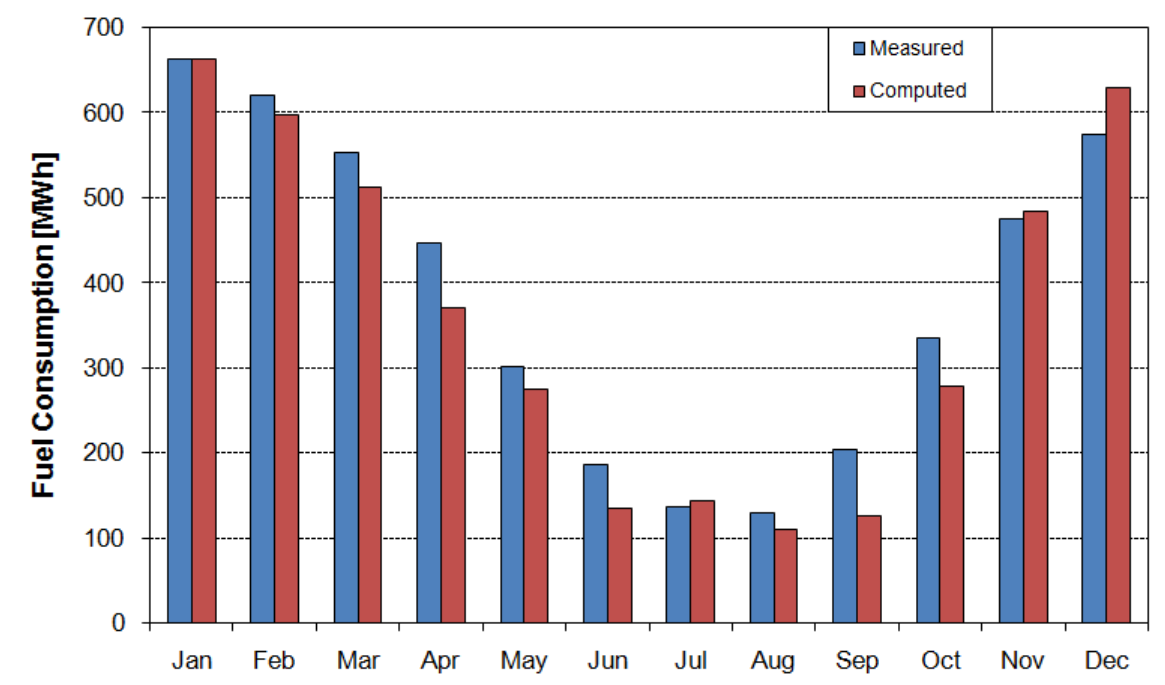

Figure 21: Disaggregation of computed electricity consumption

Total Electrical Consumption : 5250 MWh

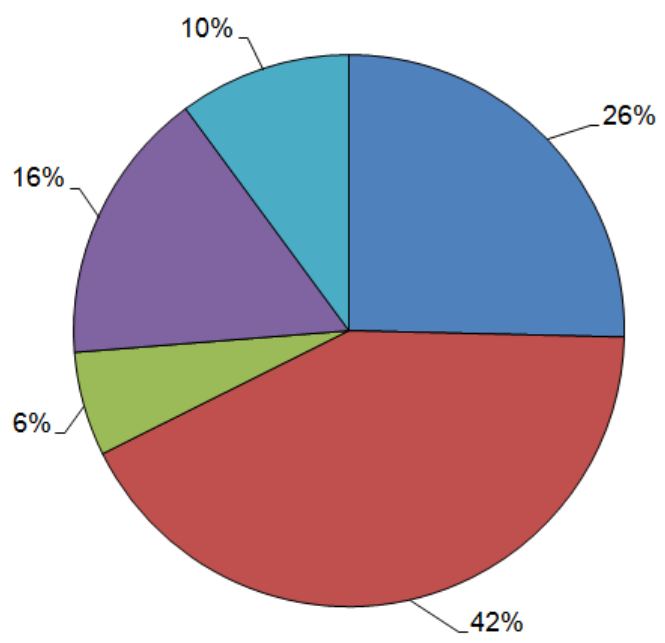

口 lighting

口appliances

- pumps

afans

achiller 
Figure 22 : Formatted equations as appearing in the software

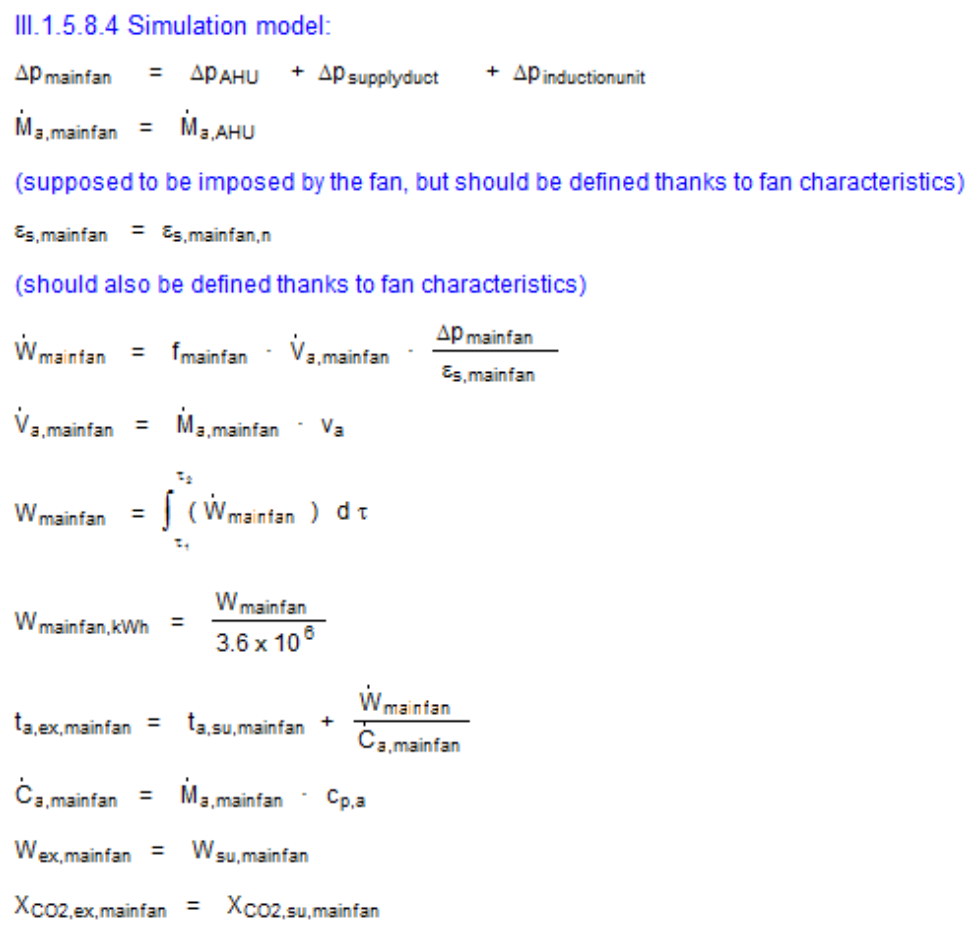


Table 1 : Main characteristics of the building

\begin{tabular}{|l|l|l|}
\hline Case Study Building & {$\left[\mathrm{m}^{2}\right]$} & 26700 \\
\hline Building conditioned floor area & {$[-]$} & 9 \\
\hline Number of storeys & {$[\mathrm{m}]$} & 30 \\
\hline Building height & - & North / South \\
\hline Main orientation & - & Brussels, Belgium \\
\hline Geographical location & {$\left[\mathrm{m}^{2}\right]$} & 7090 \\
\hline External walls area & {$[o c c]$} & 1100 \\
\hline Number of occupants & {$\left[\mathrm{W} / \mathrm{m}^{2}\right]$} & 15 \\
\hline Lighting power & {$\left[\mathrm{W} / \mathrm{m}^{2}\right]$} & 20 \\
\hline Appliances power & {$\left[\mathrm{m}^{2}\right]$} & 2570 \\
\hline Opaque frontages area & {$\left[\mathrm{W} / \mathrm{m}^{2}-\mathrm{K}\right]$} & 1.15 \\
\hline Opaque frontages U value & {$[-]$} & Light \\
\hline Opaque frontages thermal mass & {$\left[\mathrm{m}^{2}\right]$} & 2970 \\
\hline Roof deck area & {$\left[\mathrm{W} / \mathrm{m}^{2}-\mathrm{K}\right]$} & 0.32 \\
\hline Roof deck U value & {$[-]$} & $\mathrm{Light}$ \\
\hline Roof deck area thermal mass & {$\left[\mathrm{m}^{2}\right]$} & 3020 \\
\hline Double - Glazed frontages area & {$\left[\mathrm{W} / \mathrm{m}^{2}-\mathrm{K}\right]$} & 3.6 \\
\hline Double - Glazed windows U value & {$\left[\mathrm{m}^{2}\right]$} & 1440 \\
\hline Single - Glazed frontages area & {$\left[\mathrm{W} / \mathrm{m}^{2}-\mathrm{K}\right]$} & 5.8 \\
\hline Single - Glazed windows U value & & \\
\hline
\end{tabular}

Table 2 : Typical HVAC components characteristics

\begin{tabular}{|l|l|l|}
\hline \multicolumn{2}{|l|}{ HVAC components characteristics } \\
\hline Return ducts pressure drop & {$[\mathrm{Pa}]$} & 300 \\
\hline Supply ducts pressure drop & {$[\mathrm{Pa}]$} & 400 \\
\hline Filters pressure drop & {$[\mathrm{Pa}]$} & 150 \\
\hline Preheating coil pressure drop & {$[\mathrm{Pa}]$} & 80 \\
\hline Adiabatic humidifier pressure drop & {$[\mathrm{Pa}]$} & 200 \\
\hline Cooling coil pressure drop & {$[\mathrm{Pa}]$} & 140 \\
\hline Post-heating coil pressure drop & {$[\mathrm{Pa}]$} & 80 \\
\hline Fan efficiency & {$[\%]$} & 75 \\
\hline Pump efficiency & {$[\%]$} & 50 \\
\hline Boiler nominal efficiency & {$[\%]$} & 90 \\
\hline Chiller nominal COP & {$[-]$} & 3 \\
\hline Heat recovery system effectiveness & {$[\%]$} & 80 \\
\hline
\end{tabular}

